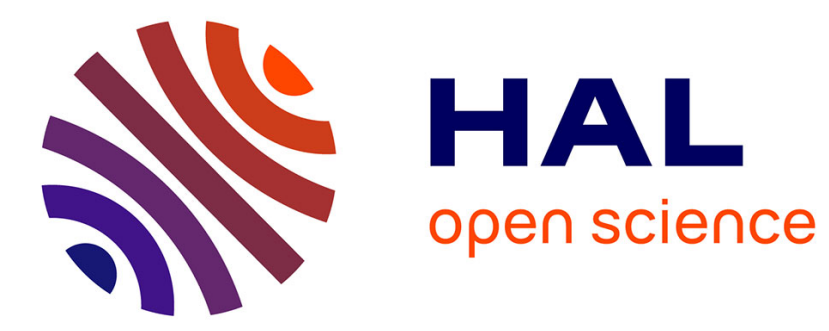

\title{
Estimating demographic parameters using hidden process dynamic models
}

Olivier Gimenez, Jean-Dominique Lebreton, Jean-Michel Gaillard, Rémi

Choquet, Roger Pradel

\section{- To cite this version:}

Olivier Gimenez, Jean-Dominique Lebreton, Jean-Michel Gaillard, Rémi Choquet, Roger Pradel. Estimating demographic parameters using hidden process dynamic models. Theoretical Population Biology, 2012, 82, pp.307 - 316. 10.1016/j.tpb.2012.02.001 • hal-03499089

\section{HAL Id: hal-03499089 \\ https://hal.science/hal-03499089}

Submitted on 24 Dec 2021

HAL is a multi-disciplinary open access archive for the deposit and dissemination of scientific research documents, whether they are published or not. The documents may come from teaching and research institutions in France or abroad, or from public or private research centers.
L'archive ouverte pluridisciplinaire HAL, est destinée au dépôt et à la diffusion de documents scientifiques de niveau recherche, publiés ou non, émanant des établissements d'enseignement et de recherche français ou étrangers, des laboratoires publics ou privés. 
4 Olivier Gimenez ${ }^{1}$, Jean-Dominique Lebreton ${ }^{1}$, Jean-Michel Gaillard ${ }^{2}$, Rémi Choquet ${ }^{1}$, and

$7{ }^{1}$ Centre d'Ecologie Fonctionnelle et Evolutive, UMR 5175, CNRS, 1919 route de Mende,

834293 Montpellier Cedex 5, France

$9{ }^{2}$ Laboratoire de Biométrie et Biologie Evolutive, Unité Mixte de Recherche 5558, Université

10 Claude Bernard Lyon I, 43 Bd du 11 novembre 1918, 69622 Villeurbanne Cedex, France

11

12 Corresponding author:

13 Olivier Gimenez, olivier.gimenez@ cefe.cnrs.fr

14 UMR 5175 - Centre d'Ecologie Fonctionnelle et Evolutive

15 1919, Route de Mende - 34293 Montpellier cedex 5, France

16 Tel: +33(0)467613211

17 Fax: +33(0)467613336

18

19

20

21 


\section{Summary}

2 Structured population models are widely used in plant and animal demographic studies to

3 assess population dynamics. In matrix population models, populations are described with

4 discrete classes of individuals (age, life history stage or size). To calibrate these models,

5 longitudinal data are collected at the individual level to estimate demographic parameters.

6 However, several sources of uncertainty can complicate parameter estimation, such as

7 imperfect detection of individuals inherent to monitoring in the wild and uncertainty in

8 assigning a state to an individual. Here, we show how recent statistical models can help

9 overcome these issues. We focus on hidden process models that run two time series in parallel,

10 one capturing the dynamic of the true states and the other consisting of observations arising

11 from these underlying possibly unknown states. In a first case study, we illustrate hidden

12 Markov models with an example of how to accommodate state uncertainty using Frequentist

13 theory and maximum likelihood estimation. In a second case study, we illustrate state-space

14 models with an example of how to estimate lifetime reproductive success despite imperfect

15 detection, using a Bayesian framework and Markov Chain Monte Carlo simulation. Hidden

16 process models are a promising tool as they allow population biologists to cope with process

17 variation while simultaneously accounting for observation error.

19 Keywords: capture-recapture; hidden Markov models; lifetime reproductive success;

20 multievent models; multistate models; state-space models; state uncertainty 


\section{INTRODUCTION}

Structured population models (Tuljapurkar \& Caswell 1997; Caswell 2001) allow a

3 detailed description of population change over time by accounting for the number of

4 individuals in discrete classes (grouped according to age, stage or state). These models are

5 widely used in plant and animal demographic studies to assess population dynamics as they

6 allow the projection of future population size, estimation of asymptotic population growth rate,

7 age structure, net reproductive rate, generation time and life expectancy among other

8 descriptive statistics. Matrix models have been used to assess population viability (e.g.,

9 Ghimire et al. 2008), evaluate the effects of management strategies on life history strategies

10 (e.g., Servanty et al. 2011) and investigate the feedback between demography and evolution

11 (van Tienderen 2000, see also Gamelon et al. [2011] for a recent application).

Traditionally, structured population models are calibrated using longitudinal data

13 collected at the individual level. These data are analyzed with statistical models to estimate

14 demographic parameters like survival, growth, dispersal and fecundity, which are then entered

15 into structured population models. However, several sources of uncertainty are associated with

16 parameter estimation that need to be properly accounted for. First, individuals are difficult to

17 monitor in the wild (mobile animals in particular) because they may or may not be observed at

18 a given sampling occasion. This raises the issue of imperfect detection, which, if ignored, can

19 lead to biased estimates and flawed inference about demographic parameters (e.g., Nichols

20 1992, Gimenez et al. 2008). Second, there can be uncertainty related to measurement error, in

21 particular, correctly assigning a state to an individual, even when the individual is observed or

22 captured. This may be the gender of an individual whenever sex is determined through

23 behavioral clues, or epidemiological status if serological tests generate false positives or

24 negatives, or reproductive status whenever the number of offspring is visually determined by

25 counting the number of young accompanying their parents. 
To handle the complexity of the dynamics of free-ranging populations and accommodate the various sources of uncertainty associated with parameter estimation, there is a need to integrate structured population models with novel statistical tools. In this paper, we aim to review and demonstrate how recent statistical models can help bring theoretical models (mechanisms) and the analysis of empirical data (patterns) together. We will focus our attention on hidden process models (see Box 1) that have recently received much attention in the literature (Buckland et al. 2004; 2007; Newman et al. 2006). In hidden process models, two time series are run in parallel: one captures the dynamic of the true (latent) states via a stochastic process model; the other is static and describes the observations that are made from these underlying but possibly unknown states.

In the first section, we review standard multistate capture-recapture models (see Box 1; Lebreton et al. 2009) that are used to estimate key demographic parameters, which are then fed to structured population models. We pay particular attention to the imperfect detection of individuals in the wild for analyzing individual longitudinal data. In the second and third sections, we reformulate longitudinal multistate models as hidden process models, either as hidden Markov models (HMM; see Box 1, Pradel 2005) or state-space models (SSM; see Box 1, Gimenez et al. 2007). In both sections, case studies are used to illustrate these models. In the second section, we show how hidden-Markov models can be used to deal with uncertainty in the assignment of reproductive status and its importance when assessing life-history trade-offs. In the third section, we show how state-space models can be used to estimate lifetime reproductive success (sensu Clutton-Brock 1988) while accounting for a detection probability less than one. Finally, we discuss the limitations of hidden process models as well as several extensions of these models.

\section{OVERVIEW OF MULTISTATE CAPTURE-RECAPTURE MODELS}


2 Capture-recapture (CR; see Box 1) models have become a central tool in population biology

3 for estimating demographic parameters under imperfect detection of individuals (Lebreton et

4 al. 1992). CR models were originally designed to estimate population size, with demographic

5 parameters such as survival probabilities progressively incorporated in these models, first as

6 nuisance parameters, and eventually as the main focus (for the early history see Lebreton et al.

72009 p. 93 ff). The standard Cormack-Jolly-Seber model (see Box 1; Cormack 1964, Jolly

8 1965, Seber 1965) is based on the embedding of two distinct processes: survival (with survival

9 probabilities denoted as $\phi$ ) and detection (with recapture probabilities denoted as $p$ ) over

10 discrete time occasions. These parameters are indexed appropriately depending on the type of

11 variation of interest (e.g., time, age or sex; Lebreton et al. 1992).

12 A notable feature of the original development of CJS models is that the survival and the

13 detection processes were viewed as intimately entangled. Adequately representing how they

14 were imbricated was indeed at the core of early methodological developments to obtain a

15 likelihood that could be used to properly estimate the parameters. For instance, under time-

16 dependence, the probability that an individual is never seen again after occasion $i$, denoted as

$17 \quad$, is obtained through a backward recurrence relationship (Cormack, 1964), accounting for

18 the fact that an individual may die between occasion $i$ and $i+1$ or survive and not be detected:

$$
{ }_{i}=1 \quad{ }_{i}+{ }_{i}\left(1 \quad p_{i+1}\right)_{i+1}
$$

20 with last occasion $=1$.

21 However, when comparing various types of detection, it clearly appeared that the survival-

22 mortality process was a background process distinct from the detection process. For instance

23 for the same time-dependent survival process, one must be able to accommodate several

24 situations illustrated in Figure 1 (see also Lebreton et al. 1999): i) complete detection, as might

25 occur in developed countries for the human population (with administrative declaration of 
1 deaths), ii) incomplete detection of live individuals, i.e., live recaptures or resightings, to be

2 analyzed with CJS models or iii) incomplete detection of deaths, as in 'dead recoveries' of

3 banded birds (usually by the general public) to be analyzed with so called dead-recovery

4 models (Brownie et al. 1985).

[Figure 1 about here]

8 In the survival process, death or survival between two sampling occasions is treated as strictly

9 conditional on the fact that the individual is alive at the onset of the target interval: the system

10 has no memory, i.e. the survival process is a Markov chain. Hence, CJS models are implicitly

11 made up of a Markov chain on top of which is an imperfect observation process (e.g., Lebreton

12 et al. 1999). In other words, CJS models are hidden process models where the demographic

13 process is represented by a (first-order) Markov chain (see next sections) that is only partially

14 observed due to imperfect detection. Conveniently, the explicit representation of the survival

15 process in CJS models as a two-state Markov chain (alive / dead) readily provides the

16 probability of individual histories, without having to use the complicated parameters

17 mentioned above (Caswell and Fujiwara 2004, pp. 477-478).

18 However, representation of the survival process as a Markov chain did not capture much

19 attention for some time for a number of reasons. First, CR models were considered to be

20 specific and exotic statistical tools, in particular because of the historical focus on population

21 size estimation and the associated difficulties in producing an adequate fully stochastic model

22 (Jolly 1965). The focus on the estimation of demographic flows developed only in the late 80s

23 (Burnham et al. 1987; Clobert and Lebreton, 1987). Second, while the succession of events

24 such as survival and death in CR models was clearly Markovian, historically, the statistical

25 point of views on CR models and Markov chains were radically different: when considering $n$ 
individuals moving over $T$ time steps according to a Markov chain, the development of stochastic process theory for Markov chains was centered on asymptotic results when $T$ tends to infinity, such as ergodicity for instance; on the contrary, CR models asymptotic results, such

4 as the optimality of maximum likelihood estimators for example, are derived for $n$ tending to

5 infinity for a fixed value of $T$. Third, parameter estimation for Markov chains under partial observation was not fully developed at that time (e.g., Lawless and McLeish 1984) and could

7 not offer solutions to the CR situation.

8 The initially slow development of the Markov chain approach to analyzing individual histories

9 is illustrated in Figure 2. The first papers explicitly using this point of view were published in

10 the early 1990s, and from there on, parallel growth in human and animal population studies

11 took place at a common rate of $\sim 9 \%$ a year.

[Figure 2 about here]

15 Modeling survival as a hidden process has several strong advantages. First, the process model can easily be made more complex or detailed to address new biological questions. Existing CR

17 extensions, such as multisite (Arnason 1972, 1973; Hestbeck et al. 1991) and recruitment

18 (Clobert et al. 1994) models, entered this common framework; new generalizations could

19 easily be produced, such as multisite recruitment models (Lebreton et al. 2003) and multistate

20 CR models (reviewed in detail by Lebreton et al. (2009), and Williams et al. 2002 pp. 454-

21 468). Second, it linked CR statistical models with parallel developments in population

22 dynamics models and notably matrix population models (Caswell 2001 p. 37). These models

23 are based on a reasonable representation of differences among individuals, through a finite

24 number of so-called 'i-state variables' that summarize relevant information on the past life of

25 an individual to determine its future in terms of, e.g., individual physiology, reproduction or

26 death (Diekmann and Heesterbeek 2000). The same idea is clearly inherent in multistate CR 
models. The empirical use of these models requires that individual data should translate into

2 parameter estimates, i.e. estimates of probabilities of the transition from, say, life to death,

3 rosette to flowering plant or non-breeder to breeder. Several papers have addressed estimation

4 and the use of estimates in multistate dynamics models (e.g., Caswell and Fujiwara 2004).

5 Third, the observation process can also be made more complex and tuned to specific situations.

6 Dupuis (1995) was among the first to distinguish clearly between the two processes in CR

7 models, considering the transitions between states as a Markov chain and imperfect detection

8 as an independent process generating 'missing data'. Soon, however, the detection process was

9 considered to be potentially more complex, e.g., with the development and systematic

10 exploration of the use of unobservable states for modeling temporary emigration (Kendall and

11 Bjorkland 2001) and recruitment (Pradel and Lebreton 1999). Specific models for 'mixtures of

12 information' (Burnham 1993) considered detection of individuals either as alive or at the time

13 of death. They appear as specific multistate CR models based on the two states alive / just dead

14 (Lebreton et al. 1999). The generalization of the observation process currently includes models

15 that account for uncertainty in the assessment of states (Kendall et al. 2003). The observation

16 process then considers a probabilistic relationship between the underlying states (such as

17 breeder vs. non-breeder) and 'events' (such as seen at nest or seen out of a nest). Hence, an

18 individual seen out of a nest may be in either state. Earlier approaches were specific to

19 permanent states (such as sex, Nichols et al. 2004), but the more general models are multistate

20 CR models that account for state uncertainty, so-called multievent models (Pradel 2005). The

21 movement towards understanding and unifying CR models as hidden process models (Figure

22 3) has followed rapidly with the development of specific statistical tools for hidden process

23 models, either hidden-Markov models or state-space models. We review these developments in

24 the following next two sections. 


\section{HIDDEN MARKOV MODELS: DEALING WITH UNCERTAINTY IN STATE} ASSIGNMENT

\subsection{Hidden-Markov modeling}

\subsubsection{HMM for capture-recapture data}

In the above multistate CR models, it is assumed that the state of an individual is

9 ascertained upon encounter. This poses no difficulty if the state is a geographical location (e.g.,

10 wintering site or breeding colony e.g.), but is less obvious when the state is reproductive status

11 (breeder or non-breeder) or a physiological state like diseased vs. healthy. Diagnosis is

12 typically attempted based upon some criterion like the presence of a brood patch or nest-

13 building activity (for a breeder) or antibody level (for a potentially diseased individual). The

14 distinction between the criterion and the state leads to models that distinguish the visible layer

15 (the criterion) from the hidden layer (the state). This distinction between what is observed and

16 what is inferred is key to hidden process models. Because the hidden layer is a first order

17 Markov chain, this naturally leads to the introduction of a HMM for analyzing CR data. The

18 key step is to recognize that whether an individual is observed or not may itself be considered

19 as belonging to the 'observable' layer. This conceptual leap led to the definition of multievent

20 CR models (see Box 1; Pradel 2005), which both generalize multistate CR models to

21 accommodate uncertainty in state assignment and firmly establish that CR models are a

22 particular type of HMMs. However, unlike in HMMs, the recorded information in multievent

23 models is named 'events' rather than 'observations', because the record can be a 'non-

24 observation'.

$25 \quad$ 3.1.2. Review of HMM applications to estimate demographic parameters 
HMMs have a tremendous potential with applications in all domains of ecology (Pradel 2009), but they historically have been seldom used. An obvious application is in epidemiology (Conn \& Cooch 2009). Another is sex identification in monomorphic or weakly polymorphic species where clues are mainly derived from behavior (Nichols et al. 2004; Pradel et al. 2010). A less obvious application is investigating the role of memory in movements among a discrete set of sites. When movements between the successive occasions are determined not only by the position occupied at a particular occasion but also by some previous positions, the previous positions must enter in the definition of the state. Then, when an individual is encountered, it may happen that because the previous relevant positions have not been observed, the exact state is unknown. This invalidates the use of multistate CR models but HMMs can be used (Rouan et al. 2009). The most elaborate application to date makes use of information from nest inspection to study the probability of skipping behavior and nest changing in a colony of Cory's shearwater (Sanz-Aguilar et al. 2011). A more methodological example is the incorporation of mark loss in mark-recapture models during a double-mark study (Juillet et al. 2011). Another interesting application copes with the issue of keeping track of the number of breeding episodes when detectability is less than one (Desprez et al. 2011; Pradel et al. 2011). It is also possible to account for tag loss and different causes of mortality (Tavecchia et al. 2012). However, by far, the greatest number of applications relates to class heterogeneity whereby a given individual belongs to a particular unknown class for the duration of the study. Cubaynes et al. (2010) emphasize the importance of explicitly modeling capture heterogeneity to avoid potentially large biases in the estimation of population size (see Ebert et al. 2010 for a review) and Crespin et al. (2008) point out that heterogeneity in capture rate may mirror social hierarchy. Véran et al. (2007) and Oliver et al. (2011) used capture heterogeneity to correct for unequal sampling over space. Péron et al. (2010a) went further by modeling class heterogeneity in survival, detection and movement simultaneously and assessed its influence on the study of senescence. Péron et al. (2010b) analyzed in further depth the significance of 
movement class heterogeneity within a population. Given all these examples, we were

2 surprised to not find studies of reproduction that account for uncertainty in the breeding status.

3 Identification of reproductive status is not always obvious and failing to acknowledge this

4 problem may lead to mistakes or at least to a loss of useful information. This issue is

5 particularly important in studies of life-history trade-offs. Here we develop an example of how

6 such data could be handled.

\subsection{Case study 1: Dealing with uncertain states}

\subsubsection{Data and models}

Data were collected between 1940 and 1957 by Lance Richdale on Sooty shearwaters

12 et al. (2001; see also Gimenez et al. 2005).

Following the way the data were collected, four states were originally considered: (1)

14 Breeder (B); (2) Keeping company with another bird in a burrow; (3) Alone in a burrow; (4)

15 On the surface. Because of numerical issues, Scofield et al. (2001) pooled 2-3-4 together in a

16 Non-Breeder state (NB) that includes failed breeders (birds that had bred previously but were

17 currently skipping reproduction or divorced) and pre-breeders (birds that had not yet bred).

18 Note that because burrows were not checked before hatching, some birds in the category NB

19 might have bred and failed before being checked. We therefore regard those birds in the B state

20 as successful breeders, and those in the NB state as a mixture of non-breeders, pre-breeders and

21 failed breeders.

We start by fitting a model with state-specific survival, detection and transition

23 probabilities between states, with all parameters constant over time. The states were \{non-

24 breeder, breeder, dead $\}=\{\mathrm{NB}, \mathrm{B}, \mathrm{D}\}$, and the events were $\{$ non-detected, detected as not a

25 successful breeder, detected as a successful breeder $\}=\{0,1,2\}$. Upon its first encounter, an

26 individual has a probability $\pi^{\mathrm{B}}$ to be a breeder and the complement probability to be a non- 
1 breeder. Then, it moves among the states according to a first-order Markov chain that can be

2 described by the state specific survival probabilities $\phi^{\mathrm{NB}}$ and $\phi^{\mathrm{B}}$ and the transition probabilities

3 conditional on survival $\psi^{\mathrm{NB} \rightarrow \mathrm{B}}$ and $\psi^{\mathrm{B} \rightarrow \mathrm{NB}}$. The state process can be represented by the

4 transition matrix with departure states in rows and arrival states in columns:

5

6

$\left[\begin{array}{clcccc}N B & N B \rightarrow N B & N B & N B \rightarrow B & 1 & N B \\ B & B \rightarrow N B & B & B \rightarrow B & 1 & B \\ 0 & 0 & & 1\end{array}\right\rfloor$.

8 Equivalently, it can be represented as the product of a survival matrix by a conditional

9 transition matrix:

10

11

$$
\left\lfloor\begin{array}{cccc}
N B & 0 & 1 & N B \\
0 & B & 1 & B \\
0 & 0 & & 1
\end{array}\right\rfloor \times\left\lfloor\begin{array}{lll}
N B \rightarrow N B & N B \rightarrow B & 0 \\
B \rightarrow N B & B \rightarrow B & 0 \\
0 & 0 & 1
\end{array}\right\rfloor .
$$

13 The event process conditional on underlying states is described via the detection probabilities

$14 \mathrm{p}^{\mathrm{NB}}$ and $\mathrm{p}^{\mathrm{B}}$. This event can be summarized by a row-stochastic matrix (i.e., probabilities in a

15 row sum up to one) with states in rows and events in columns:

16

17

$$
\begin{array}{cccc}
1 & p^{N B} & p^{N B} & 0 \\
1 & p^{B} & 0 & p^{B} \\
1 & 0 & 0
\end{array} .
$$

19 For instance, in row 1 column 2 is the probability that a non-breeder is detected as not a

20 successful breeder $\mathrm{p}^{\mathrm{NB}}$. 
To demonstrate how uncertain detection of reproductive status could be analyzed, we

2 generated uncertainty in the assignment of Non-Breeder vs. Breeder as follows. For each

3 individual at each detection occasion: a Non-Breeder was assumed to be judged a Non-Breeder

4 with probability 0.2 (and assigned to event 1 ), and not judged with the complementary

5 probability 0.8 (and assigned to the ambiguous event 3), while a Breeder was assumed to be

6 judged a Breeder with probability 0.7 (and then assigned to event 2), and not judged with the

7 complementary probability 0.3 (and assigned to event 3 ). This procedure was implemented in

8 R (R Development Core Team 2011; see Appendix A2). To analyze these imperfect data, only

9 the event process changes. In addition to the detection probabilities, we add state-specific

10 probabilities of breeding state assignment $\delta^{\mathrm{NB}}$ and $\delta^{\mathrm{B}}$. With the same presentation as before, the

11 event process becomes:

$$
\begin{array}{cccccc}
1 & p^{N B} & p^{N B} & 0 & p^{N B}(1 & \left.{ }_{N B}\right) \\
1 & p^{B} & 0 & p^{B}{ }_{B} & p^{B}(1 & \left.{ }_{B}\right) \\
1 & 0 & 0 & 0 &
\end{array} .
$$

15 Note that the new event 'breeding state not ascertained' (column 4) can arise for non-breeders

16 (first row) as well as breeders (second row), though with potentially different probabilities.

17 This matrix can also be written as a product of two matrices, highlighting the successive

18 processes of detection and breeding state ascertainment:

\begin{tabular}{|c|c|c|c|c|c|c|c|}
\hline $1 p^{N B}$ & $p^{N B}$ & 0 & 1 & 0 & 0 & & ) \\
\hline $1 p^{B}$ & 0 & $p^{B}$ & 0 & $N B$ & 0 & 1 & $N B$ \\
\hline 1 & 0 & 0 & 0 & 0 & $B$ & 1 & $B$ \\
\hline
\end{tabular}

19

22 Note that when the animal is first encountered, the capture process is not modeled because an 
1 animal must be encountered at least once to enter the data set. But the reproductive state

2 ascertainment remains valid. Models with or without imperfect assignment of reproductive

3 state were implemented in the freely downloadable program E-SURGE (Choquet et al. 2009;

4 see Appendix A1 for details).

5

6

8 the considerable loss of information due to uncertain state, in particular for the non-breeders

9 which are recognized as such only $20 \%$ of the time (Table 1). The estimates of other

10 parameters remain similar to those of the original model. The most notable and logical change

11 is a loss of precision. However, in a real study, there would probably be on the contrary a gain

12 of precision because the data chosen for analysis with multistate models are those deemed most

13 reliable. In contrast, the model with uncertainty would be run on the larger dataset that includes

14 the less reliable data. For this reason, precision should be enhanced by explicitly dealing with

15 breeding state uncertainty.

16

17

18

[Table 1 about here]

\section{STATE-SPACE MODELS: ESTIMATING LIFETIME REPRODUCTIVE SUCCESS}

\subsection{State-space modeling}

\subsubsection{SSM for capture-recapture data}

Parallel to the HMM formulation of CR models, there has been increasing use of statespace models (SSM) to handle data on marked individuals. State-space models are a generalization of hidden Markov models in that the states are not necessarily governed by a Markov process. In practice, parameters of SSMs have been estimated in a Bayesian 
1 framework (using Markov Chain Monte Carlo [MCMC] simulation of the joint posterior

2 distribution of parameters; see section 4.2.3) while HMM have been fit in a Frequentist

3 framework using maximum likelihood methods. CR models were reformulated as SSMs by

4 several authors (Gimenez et al., 2007; Royle, 2008; Schofield and Barker, 2008) to distinguish

5 the underlying demographic process from the observation process.

6

\subsubsection{Use of SSMs to estimate demographic parameters data - a survey}

The SSM formulation provides a great deal of flexibility and has led to substantial progress in modeling key demographic parameters. Link and Barker (2005) showed how to estimate correlations between demographic parameters such as survival and reproductive rates. Servanty et al. (2010) used this approach to estimate cause-specific mortalities and test for additivity in mortality. Other applications include comparisons among species (Papadatou et al., 2011), spatial structure (Péron et al., 2011) and the study of migration (Calvert et al., 2009; O'Hara et al., 2009). Demographic parameters can be estimated for species with complex life cycles using SSMs (Clark et al., 2005; Buoro et al., 2010). Like HMM, important developments included the incorporation of individual heterogeneity via random effects (Schofield and Barker, 2011; Royle, 2008; Marzolin et al., 2011; see Gimenez and Choquet 2010 for an implementation of individual random effects in HMM). In addition, Gimenez et al. (2006; 2009) used SSM to estimate selection gradients and visualize fitness surfaces based on capture-recapture data, while Papaïx et al. (2010) showed how to estimate components of phenotypic variance that can be attributed to genetic factors, environmental factors and other unknown factors, hence quantifying heritability of demographic parameters. All these applications have used SSM to estimate demographic parameters. However, SSM also allows the estimation of the unknown latent states. To our knowledge, this has rarely been attempted, although it could be useful in reconstructing individuals' fates and population dynamics

(Gimenez et al., in prep). We develop an example of this below. 
4.2. Case study 2: Measuring Lifetime Reproductive Success in the wild

4

\subsubsection{Estimating fitness in the wild can be difficult}

Lifetime Reproductive Success (LRS), the number of young measured at some stage by an individual during its lifespan is a single-generation measure of the individual's contribution to future generations (Clutton-Brock, 1988; Newton, 1989) and thus provides a reliable measure of individual fitness (see Brommer et al. 2004 for an empirical demonstration). The estimation of LRS requires information on the number of offspring an individual has produced and successfully raised at some stage (e.g., born, weaned or fledged, first reproducing) at each reproductive attempt. In theory then, exhaustive monitoring of individuals over their whole reproductive life is needed to estimate LRS. In the field, however, estimating LRS is difficult, because individuals are typically observed (or recaptured) only a fraction of their lifetime. In years when a given individual is not observed, whether it gives birth or not and how many offspring it produces at birth or at the end of the parental care period if it does breed remain unknown. In the following section, we show that, by considering two states (breeder vs. nonbreeder) with the associated number of offspring produced in a SSM, reliable estimates of LRS can be obtained while accounting for detection probability less than one. A similar approach was proposed by Rouan et al. (2009b) who used HMM to compute LRS.

\subsubsection{Data and models}

We illustrate our approach using the reproductive histories of 211 female roe deer that were monitored in the Trois Fontaines forest, North-East France, between 1976 and 2006 (see e.g. McLoughlin et al. 2007 for further details about this monitoring). We developed a CR model to analyze these live recaptures of female roe deer. In line with recent work by Gimenez 
et al. (2007), Royle (2008) and Schofield and Barker (2008), we used a state-space formulation

2 of CR models that explicitly separates the demographic process of interest (survival status in a

3 particular reproductive state) from the observations (the data). We considered five states: alive

4 non-breeder (NB), alive and weaning one fawn (B1), alive and weaning two fawns (B2), alive

5 and weaning three fawns (B3) and dead (D). We denoted $X_{i, t}$ the random state vector taking

6 values $(1,0,0,0,0),(0,1,0,0,0),(0,0,1,0,0),(0,0,0,1,0),(0,0,0,0,1)$ if, at time $t$, individual $i$ is in

7 state NB, B1, B2, B3 or D, respectively. Based on the roe deer life history (see e.g. Gaillard et

8 al. 1998), we considered several possible observations that were generated from these

9 underlying states: the animal is not seen (coded 0$)$, the animal is seen without any fawn (coded

10 1), the animal is seen with one fawn (coded 2), the animal is seen with two fawns (coded 3)

11 and the animal is seen with three fawns (coded 4) in the dataset. We denoted $Y_{i, t}$ the random

12 observation vector taking values $(1,0,0,0,0),(0,1,0,0,0),(0,0,1,0,0),(0,0,0,1,0),(0,0,0,0,1)$ if, at

13 time $t$, individual $i$ is not seen or seen with zero, one, two or three fawns respectively.

15 alive at time $t$ in state $k=\mathrm{NB}$ (non-breeder) or B (breeder whatever the number of fawns

16 weaned) survives to time $t+1$. Age-dependence in $\underset{i, t}{k}$ was modeled using three classes:

17 yearling (1 to 2 years), prime-aged ( 2 to 5 years) and old adults (6 years and older) according

18 to previous survival analyses (see e.g. Gaillard et al. 1993). We also modeled the probability

$19 \underset{i, t}{k \rightarrow k^{\prime}}$ that an individual $i$ makes a transition between states $k$ and $k^{\prime}\left(k, k^{\prime}=\mathrm{NB}, \mathrm{B} 1, \mathrm{~B} 2\right.$ or B3)

20 between occasion $t$ and $t+1$. Finally, we considered the probability $p_{i, t}^{k}$ that an individual $i$ is

21 recaptured at time $t$ in state $k=\mathrm{NB}$ or $\mathrm{B}$. Note that, although it is possible, we do not consider

22 individual effects on these parameters, so that the index $i$ is dropped hereafter.

The state-space model relies on a combination of two sets of equations: the state

24 equations, which specify the state of individuals at time $t+1$ given their state at time $t$, and the 
1 observation equations, which specify the observation of individuals at time $t$ given their state at

2 time $t$. The state-space formulation of the CR model (Gimenez et al. 2007) is given by:

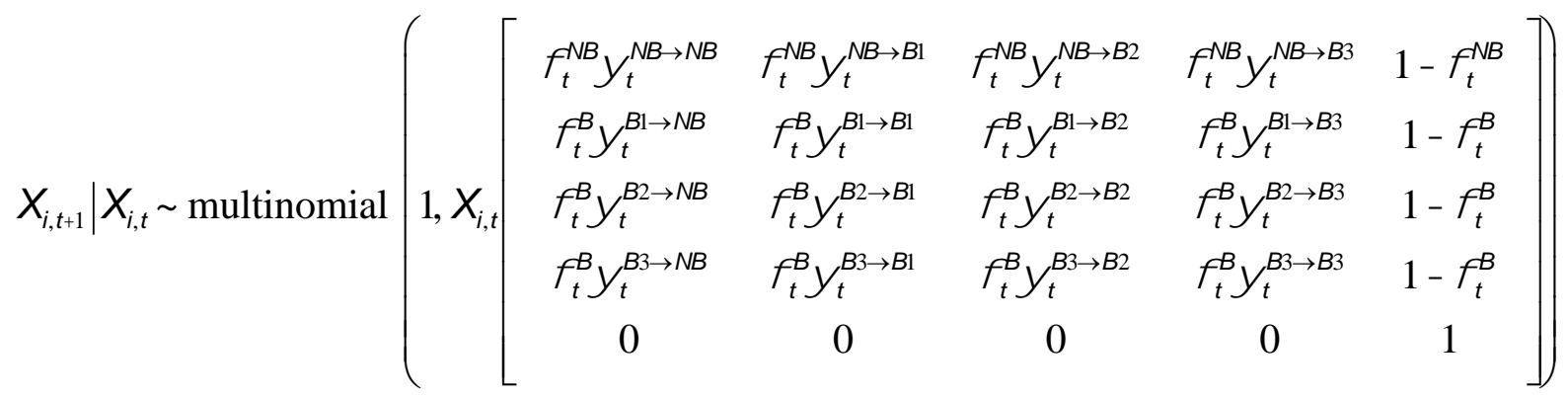

3 and

$$
Y_{i, t} \mid X_{i, t} \sim \text { multinomil }\left(1, X_{i, t}\left[\begin{array}{ccccc}
1-p_{t}^{N B} & p_{t}^{N B} & 0 & 0 & 0 \\
1-p_{t}^{B} & p_{t}^{B} & 0 & 0 & 0 \\
1-p_{t}^{B} & 0 & p_{t}^{B} & 0 & 0 \\
1-p_{t}^{B} & 0 & 0 & p_{t}^{B} & 0 \\
1-p_{t}^{B} & 0 & 0 & 0 & p_{t}^{B}
\end{array}\right]\right)
$$

4 where the two equations above are the state and the observation equations, respectively. In the

5 state equation, the matrix gathers the conditional probabilities of being in a state at a particular

6 time occasion (columns) given the state at the previous time occasion (rows). Given that an

7 individual is alive in a given state, it can survive and move to another state, survive and remain

8 in the same state or die. To ensure that these probabilities are within the interval $[0,1]$ and sum

9 to 1 , we used a generalized (or multinomial) logit link function for the transition probabilities

10 (Choquet 2008). Consider for example the four transition probabilities from state NB to one of

11 the four states NB, B1, B2 and B3. We considered the probability of remaining in the same

12 state as a reference (one minus the sum of the three other transition probabilities) and used the

13 transformation $\log \left(\frac{\psi_{t}^{N B \rightarrow k}}{\psi_{t}^{N B \rightarrow N B}}\right)$ for $k=\mathrm{B} 1, \mathrm{~B} 2$ or B3 (see Appendix B for technical details). In

14 the observation equation, the matrix gathers the conditional probability of being observed or

15 not at a particular time occasion (columns) given the state at this current occasion (rows).

16 Given that an individual is alive in state non-breeder or breeder, it can be recaptured or not in 
state non-breeder or breeder respectively. Given that an individual is dead, it is missed with certainty. We had also to specify the probability of being in a given state when first captured.

3 Because first reproduction starts at 2 years in roe deer (Gaillard et al., 1992) and females are

4 marked in their first winter at about 8 months of age (hence as non-breeder, Gaillard et al.

5 1993), we considered the probability of being in the state non-breeder when first captured to be 6 unity, and null for any other state.

\subsubsection{Estimation of LRS using MCMC methods in a Bayesian framework}

We used MCMC simulations in a Bayesian context (McCarthy 2007; King et al. 2009;

10 Kéry and Schaub 2011; Royle and Dorazio 2008; Link and Barker 2011) to fit the above SSM.

11 Prior distributions need to be specified for the parameters of a given model. Bayes' theorem is

12 then used to update the priors using the likelihood to obtain posterior probabilities of all model

13 parameters. The MCMC algorithm then generates values from a Markov chain whose

14 stationary distribution is the joint posterior distributions of all model parameters. We used

15 empirical means and standard deviations to summarize these posterior parameter distributions.

A nice feature of MCMC algorithms is that reproductive states can be treated as

17 parameters to be estimated, just like survival, transition or recapture probabilities (see Newman

18 et al. 2008 and Toni et al. 2009 for alternatives to MCMC). We produced posterior

19 distributions for breeding states of individuals, which were used to calculate LRS. Specifically,

20 for each MCMC iteration, we calculated for each individual the number of fawns it weaned per

21 time step and then computed an average over all (post burn-in) iterations for each of the

22 females. Summarizing across individuals, we obtained the frequency distribution of LRS. We

23 quantified uncertainty around the LRS estimate by computing a 'mean' standard deviation

24 which was obtained as an average, for a particular value of reproductive output, of all the

25 individual LRS standard deviation for individuals having this specific number of offspring (see

26 Appendix B for more details). 
We provided vague prior distributions for all model parameters to induce little prior

2 knowledge. Specifically, we chose uniform distributions on $[0,1]$ for the recapture and

3 survival probabilities, and normal distributions with mean zero and variances 0.01 for the logit

4 of the transition probabilities. We conducted a sensitivity analysis by modifying these priors

5 using beta distributions with informative moments and posterior estimates of parameters were

6 not changed.

Two MCMC chains with over-dispersed initial values were generated using 50,000

8 iterations with 10,000 burn-in iterations. Convergence was assessed using the Gelman and

9 Rubin statistic, which compares the within- to the between-variability of chains started at

10 different and dispersed initial values (Gelman 1996). Mixing was checked visually by

11 inspecting the chains. The simulations were performed using JAGS (Plummer 2003) and the R

12 package rjags was used to call JAGS, export results in R and calculate LRS. The code is

13 available in Appendix B.

14

18 less prone to recapture than non-breeders. Survival decreased with increasing age, regardless of

19 reproductive status.

[Table 2 about here]

23 Much of the density of the distribution of LRS falls at zero (Figure 4): there were many

24 individuals that did not successfully wean any fawns over their entire lifetime. We also

25 observed a long tail in the LRS distribution, suggesting that some females had very high

26 reproductive output. 
[Figure 4 about here]

\section{DISCUSSION}

Multistate CR models are a valuable tool for estimating demographic parameters in the

9 wild when detection probability is less than one. Their extension to hidden process models

10 allows improved estimation of demographic parameters by accounting for variation in the state

11 process (e.g., demographic stochasticity) while dealing with observation error. Using the same

12 data that one would analyze with multistate models, SSM allows the estimation of

13 demographic parameters as well as unknown states with imperfect detection (a feature we used

14 to estimate LRS in section 4.2). By optimizing the use of all available information including

15 those data that could not be used in multistate analyses, HMM allow us to cope with

16 uncertainty in state assignment (section 3.2).

Traditionally, in the CR literature, HMM are fit in a Frequentist framework while SSM

18 are fitted in a Bayesian framework. This does not need to be the case (de Valpine 2009), and

19 examples of Frequentist analyses of SSMs are becoming available (Lele et al. 2007; de Valpine

20 2011). We advocate pragmatism when making the decision of one framework over the other

21 (Gimenez 2008). This decision can be made based on one's programming skills or familiarity

22 with software. However, there is a risk of using a sledgehammer to crack a nut by fitting

23 unnecessarily complex models that come with difficulties (Bolker 2009; Cressie et al. 2009)

24 like non-identifiability for example (Gimenez et al. 2003, 2009; Luo et al. 2009; Rouan et al.

25 2009a). We encourage practitioners to think first of the biological question to be addressed, and

26 resort to the Bayesian or Frequentist approach accordingly. For example, in the roe deer 
example (section 4.2), we aimed at estimating LRS. We opted for SSM fit in a Bayesian

2 framework using MCMC methods because it allowed the simultaneous estimation of unknown

3 reproductive states and demographic parameters while accounting for parameter estimation

4 error (Figure 2). We could have used Frequentist alternatives to compute LRS (as shown by

5 Rouan et al. 2009b).

In the roe deer data analysis (section 4.2), we assumed that uncertainty in assessing the

7 reproductive status was due to the issue of detection only: if a female was seen in the field, its

8 reproductive status corresponded to the observation made. This was a fair assumption since

9 fawns closely follow their mother during the period considered (Gaillard et al. 2000). However,

10 if this assumption were to be violated, one could easily incorporate uncertainty in state

11 assignment in the calculation of LRS by adapting the model used in the titis data analysis

12 (section 3.2).

13 We reviewed two types of hidden process models, both having a discrete space of

14 states. Continuous hidden process models have never been used to our knowledge but could be 15 useful in fitting an alternative to matrix models known as integral projection models developed

16 by Easterling et al. (2000) for plant populations. In contrast with matrix models, which require

17 discretizing individuals' states into classes, demographic parameters are modeled as continuous

18 functions of individuals' states in integral projection models (e.g., size in plants or body mass

19 in animals). Continuous hidden process models could be used as a unifying framework to

20 combine the analysis of individual data, the construction of integral projection models and the

21 projection of population fate by considering relevant states as being continuous.

The extension of hidden process models to the analysis of other sources of information

23 than individual data also holds promise. In particular, Besbeas et al. (2002) developed an

24 integrated framework to jointly analyze individual data using CR models and count data

25 collected at the population level. So-called integrated population models use hidden process

26 models to build the likelihood of count data (e.g., Schaub et al. 2007), while standard product- 
1 multinomials are used to form the likelihood of capture-recapture data. The formulation of

2 integrated population models in a unifying framework using HMM or SSM for both count and

3 individual data would certainly benefit from the flexibility of hidden process models.

4

\section{ACKNOWLEDGMENTS}

7 The authors warmly thank Mathieu Buoro for his help with Figure 3, Lauriane Rouan for

8 discussion about LRS calculation using capture-recapture data, Paul Scofield and David

9 Fletcher for sharing the titis data, Jean-Michel Marin and Christian Robert for a discussion

10 about the distinction between HMM and SSM. We also thank the participants to the 2009 and

112010 Montpellier workshops on the analysis of capture-recapture data for their feedback on the

12 titis analyses. This research was supported by a grant (reference: ANR-08-JCJC-0028-01) from

13 the 'Jeunes Chercheuses et Jeunes Chercheurs' program of the French ANR to work on

14 capture-recapture mixed models.

15

16

17 
2 Arnason, A.N. (1972) Parameter estimates from mark-recapture experiments on two populations subject to migration and death. Researches on Population Ecology 13:97-113.

4 Arnason, A.N. (1973) The estimation of population size, migration rates and survival in a stratified population. Researches on Population Ecology 15:1-8.

Besbeas, P., S. N. Freeman, B. J. T. Morgan, and E. A. Catchpole (2002). Integrating markrecapture-recovery and census data to estimate animal abundance and demographic parameters. Biometrics 58:540-547.

Bolker, B. (2009). Learning hierarchical models: advice for the rest of us. Ecological

(1)
Applications 19:588-592.

Brommer, J. E., L. Gustafsson, H. Pietiäinen and J. Merilä (2004). Single-generation estimates

(1)
of fitness as proxies for long-term genetic contribution. American Naturalist 163:505-517.

Brownie, C., Anderson, D.R., Burnham, K.P. \& Robson, D.S. (1985) Statistical inference from band recovery data - A handbook. US Fish and Wildlife Service Editions.

Buckland, S.T., Newman, K.B., Thomas, L., and Koesters, N. (2004). State-space models for the dynamics of wild animal populations. Ecological Modelling 171:157-175.

Buckland, S.T., Newman, K.B., Fernandez, C., Thomas, L., and Harwood, J. (2007). Embedding population dynamics models in inference. Statistical Science 22:44-58.

19 Burnham, K.P. (1993) A theory for combined analysis of ring recovery and recapture data. Marked individual in the study of bird population. (eds J.D. Lebreton \& P.M. North), pp.

Burnham, K.P., D.R. Anderson, G.C. White, C. Brownie, and K.H. Pollock (1987). Design and analysis methods for fish survival experiments based on release-recapture. American Fisheries Society Monograph 5. 437 pp. 
Buoro, M., Prévost, E. and O. Gimenez (2010). Investigating evolutionary trade-offs in wild populations of Atlantic salmon (Salmo salar): incorporating detection probabilities and individual heterogeneity. Evolution 64: 2629-2642

Calvert, A., S. Bonner, I. Jonsen, J. Flemming, S. Walde, and P. Taylor. 2009. A hierarchical Bayesian approach to multi-state mark-recapture: simulations and applications. Journal of Applied Ecology 46:610-620.

Caswell, H., Matrix population models: Construction, analysis and interpretation. Second Edition. 2001, Sunderland, Massachusetts: Sinauer Associates.

9 Caswell, H. \& Fujiwara, M. (2004) Beyond survival estimation: mark-recapture, matrix population models, and population dynamics. Animal Biodiversity and Conservation 27.1:471-488.

Choquet, R. 2008. Automatic generation of multistate capture-recapture models. The Canadian Journal of Statistics 36:1-15.

Choquet R., Rouan L. \& Pradel R. (2009). Program E-SURGE: a software application for

15
fitting multievent models. In: Modeling Demographic Processes in Marked Populations (eds. Thomson DL, Cooch EG \& Conroy MJ). Springer Berlin, Germany, pp. 845-865.

Clark, J. S., G. Ferraz, N. Oguge, H. Hays, and J. Dicostanzo. 2005. Hierarchical bayes for structured, variable populations: from recapture data to life-history prediction. Ecology $86: 2232-2244$.

Clobert J. and Lebreton J.-D. (1987). About recent research in models for mark-recapture and mark-resighting data. A reply to C. Brownie. Biometrics 43:1019-1022.

Clobert, J., Lebreton, J.-D., Allaine, D. \& Gaillard, J.M. (1994) The estimation of age-specific breeding probabilities from recaptures or resightings of marked animals. II Longitudinal models. Biometrics 50:375-387.

Clutton-Brock, T. H. (1988). Reproductive Success. Studies of Individual Variation in 
Conn, P.B. and E.G. Cooch. (2009) Multistate capture-recapture analysis under imperfect state observation: an application to disease models. Journal of Applied Ecology 46, 486-492.

Cormack, R.M. (1964) Estimates of survival from the sighting of marked animals. Biometrika $51: 429-438$.

Crespin L., Choquet R., Lima M.A., Merritt J.F. \& Pradel R. (2008) Is heterogeneity of catchability in capture-recapture studies a mere sampling artifact or a biologically relevant feature of the population? Population Ecology 50:247-256.

Cressie, N., C.A. Calder, J.S. Clark, J.M.V. Hoef and C.K. Wikle (2009). Accounting for uncertainty in ecological analysis: the strengths and limitations of hierarchical statistical modelling. Ecological Applications 19:553-570

Cubaynes S., Pradel R., Choquet R., Duchamp C., Gaillard J.-M., Lebreton J.-D., Marboutin E., Miquel C., Reboulet A.-M., Poillot C., Taberlet P. \& Gimenez O. (2010). Importance of accounting for detection heterogeneity when estimating abundance: The case of French wolves. Conservation Biology 24:621-626.

Desprez, M. R. Pradel, E. Cam, J.-Y. Monnat \& O. Gimenez (2011). Now you see him, now you don't: Experience, not age, is related to reproduction in Kittiwakes. Proceedings of the Royal Society B: Biological Sciences 278:3060-3066

Diekmann, O. and Heesterbeek, J.A.P. (2000) Mathematical Epidemiology of Infectious Diseases: Model Building, Analysis and Interpretation. Wiley, New York.

Dupuis, J.A. (1995) Bayesian estimation of movement and survival probabilities from capturerecapture data. Biometrika 82:761-772.

Ebert C., Knauer F., Storch I. \& Hohmann U. Individual heterogeneity as a pitfall in population estimates based on non-invasive genetic sampling: a review and recommendations. Wildlife Biology 16:225-240.

Easterling, M.R., S. P. Ellner, and P. M. Dixon. 2000. Size-specific sensitivity: applying a new structured population model. Ecology 81:694-708. 
Gaillard, J. M., Sempéré, A. J., Boutin, J. M., Van Laere, G., and Boisaubert, B. (1992).

.
Effects of age and body weight on the proportion of females breeding in a population of roe deer (Capreolus capreolus). Canadian Journal of Zoology 70:1541-1545.

Gaillard, J. M., Andersen, R., Delorme, D., and Linnell, J. (1998). Family effects on growth and survival of juvenile roe deer. Ecology 79:2878-2889.

Gaillard, J. M., Festa-Bianchet, M., Delorme, D., and Jorgenson, J. (2000). Body mass and individual fitness in female ungulates: bigger is not always better. Proceedings of the Royal Society of London, Series B 267:471-477.

Gamelon, M., A. Besnard, J.-M. Gaillard, S. Servanty, E. Baubet, S. Brandt and O. Gimenez (2011). High hunting pressure selects for earlier birth data: Wild boar as a case study. Evolution 65: 3100-3112.

Gelman, A. 1996. Inference and monitoring convergence. Pages 131-143 in W. R. Gilks, S. Richardson, and D. J. Spiegelhalter, editors. Markov Chain Monte Carlo in practice. Chapman and Hall, London, UK.

Ghimire, S., Gimenez, O., Pradel, R., McKey, D., and Y. Aumeeruddy-Thomas (2008). Demographic variation and population viability in a threatened Himalayan medicinal and aromatic herb (Nardostachys grandiflora): matrix modelling of harvesting effects in two contrasting habitats. Journal of Applied Ecology 45: 41-51.

Gimenez O., Choquet R., Lamor L., Scofield P., Fletcher D., J.-D. Lebreton and R. Pradel (2005). Efficient Profile-Likelihood Confidence Intervals for Capture-Recapture Models. Journal of Agricultural, Biological, and Environmental Statistics 10: 184-196.

Gimenez, O., R. Covas, C. R. Brown, M. D. Anderson, M. Bomberger Brown and T. Lenormand. (2006). Nonparametric estimation of natural selection on a quantitative trait using mark-recapture data. Evolution 60: 460-466 
1 Gimenez, O., V. Rossi, R. Choquet, C. Dehais, B. Doris, H. Varella, J.-P. Vila, and R. Pradel. (2007). State-space modelling of data on marked individuals. Ecological Modelling 206:431-438.

4 Gimenez, O. (2008). Discussion: Towards a Bayesian analysis template? The Canadian Journal of Statistics 36: 21-24.

Gimenez, O., A. Viallefont, A. Charmantier, R. Pradel, E. Cam, C. R. Brown, M. D. Anderson, M. Bomberger Brown, R. Covas, J.-M. Gaillard (2008). The risk of flawed inference in evolutionary studies when detectability is less than one. The American Naturalist 172:441448.

10 Gimenez, O., Morgan, B.J.T. and S.P. Brooks (2009). Weak Identifiability in Models for Mark-

11 Recapture-Recovery Data.In Modeling Demographic Processes in Marked Populations.

$$
\text { Thomson, D. L.; Cooch, E. G.; Conroy, M. J. (Eds.). Springer Series: Environmental and }
$$

$$
\text { Ecological Statistics, Vol. 3, pages 1055-1067. }
$$

Gimenez, O. and R. Choquet (2010) Incorporating individual heterogeneity in studies on marked animals using numerical integration: capture-recapture mixed models. Ecology 91:

$$
951-957
$$

Hestbeck, J.B., Nichols, J.D. and Malecki, R. (1991) Estimates of movement and site fidelity using mark-resight data of wintering canada geese. Ecology 72:523-533

Jolly, G.M. (1965) Explicit estimates from capture-recapture data with both death and immigration-stochastic model. Biometrika 52:225-247

Juillet C., Choquet R., Gauthier G. and Pradel R. (2011). A capture-recapture model with double-marking, live and dead encounters, and heterogeneity of reporting due to auxiliary mark loss. Journal of Agricultural, Biological and Environmental Statistics 16:88-104

Kendall, W.L. and Bjorkland, R. (2001) Using open robust design models to estimate temporary emigration from capture-recapture data. Biometrics 57:1113-1122 
Kendall W.L., Hines J.E., Nichols J.D. (2003). Adjusting multistate capture-recapture models for misclassification bias: Manatee breeding proportions. Ecology 84:1058-1066

Kéry, M. and Schaub, M. 2011. Bayesian population analysis using WinBUGS - a hierarchical perspective. Academic Press.

King, R., Morgan, B.J.T., Gimenez, O. and S.P. Brooks. 2009. Bayesian analysis for population ecology. Chapman and Hall.

Lawless, J.F. and McLeish, D.L. (1984) The information in aggregate data from Markov chains. Biometrika 71:419-430.

Lebreton, J.-D., Burnham, K.P., Clobert, J. and Anderson, D.R. (1992) Modeling survival and testing biological hypotheses using marked animals: a unified approach with case studies. Ecological Monographs 62:67-118.

Lebreton, J.-D., Almeras, T. and Pradel, R. (1999) Competing events, mixtures of information and multistrata recapture models. Bird Study 46:39-46.

Lebreton, J.-D., Hines, J.E., Pradel, R., Nichols, J.D. and Spendelow, J.A. (2003) Estimation by capture-recapture of recruitment and dispersal over several sites. Oikos 101:253-264. Lebreton, J. -D., J. D. Nichols, R. J. Barker, R. Pradel, and J. A. Spendelow. 2009. Modeling individual animal histories with multistate capture-recapture models. Pages $87-173$ in H. Caswell, editor. Advances in Ecological Research, 41. Academic Press, Burlington, MA. Lele, S. R., B. Dennis, and F. Lutscher (2007). Data cloning: easy maximum likelihood estimation for complex ecological models using Bayesian Markov chain Monte Carlo methods. Ecology Letters 10:551-563.

2 Link, W. A. and R. J. Barker. 2005. Modeling association among demographic parameters in open population capture-recapture data. Biometrics 61:46-54

Link, W. A. and Barker, R. J. (2010) Bayesian inference with ecological applications. Academic Press. 
Luo, Y.Q., E.S. Wend, X.W. Wu, C. Gao, X.H. Zhou and L. Zhang (2009). Parameter

identifiability, constraint, and equifinality in data assimilation with ecosystem models

Ecological Applications 19:571-574

Marzolin, G., A. Charmantier and O. Gimenez (2011). Frailty in state-space models: application to actuarial senescence in the dipper. Ecology 92:562-567

McCarthy, M. A. (2007) Bayesian methods for ecology. Cambridge University Press, Cambridge, UK.

McGraw, J. B. and Caswell, H. (1996). Estimation of individual fitness from life-history data. American Naturalist 147:47-64.

McLoughlin, P. D., J.-M. Gaillard, M. S. Boyce, C. Bonenfant, F. Messier, P. Duncan, D. Delorme, B. Van Moorter, S. Said and F. Klein (2007). Lifetime reproductive success and composition of the home range in a large herbivore. Ecology 88:3192-3201.

Newman, K.B., Buckland, S.T., Lindley, S.T., Thomas, L., and Fernandez, C. (2006). Hidden process models for animal population dynamics. Ecological Applications 16:74-86.

Newton, I., ed. (1989) Lifetime Reproduction in Birds. Academic Press, London.

Nichols, J.D. (1992). Capture-recapture models. Bioscience 42:94-102.

Nichols J.D., Kendall W.L., Hines J.E. \& Spendelow J.A. (2004). Estimation of sex-specific survival from capture-recapture data when sex is not always known. Ecology 85:31923201.

O'Hara, R., S. Lampila, and M. Orell. 2009. Estimation of rates of births, deaths, and immigration from mark-recapture data. Biometrics 65:275-281

Oli, M.K., M. Venkataraman, P. A. Klein, L. D. Wendland and M. B. Brown (2006). Population dynamics of infectious diseases: A discrete time model. Ecological Modelling 198: 183-194.

Oliver L.J., Morgan B.J.T., Durant S.M. \& Pettorelli N. Individual heterogeneity in recapture probability and survival estimates in cheetah. Ecological Modelling 222:776-784. 
Papadatou, E., R. Pradel, M. Schaub, D. Dolch, H. Geiger, C. Ibañez, G. Kerth, A. PopaLisseanu, W. Schorcht, J. Teubner and O. Gimenez (2011). Comparing survival among species with imperfect detection using multilevel analysis of mark-recapture data: a case study on bats. Ecography [doi: 10.1111/j.1600-0587.2011.07084.x]

Papaïx, J., S. Cubaynes, M. Buoro, A. Charmantier, P. Perret and O. Gimenez (2010). Combining capture-recapture data and pedigree information to assess heritability of demographic parameters in the wild. Journal of Evolutionary Biology 23: 2176-2184

Péron, G., Y. Ferrand, F. Gossmann, C. Bastat, M. Guenezan and O. Gimenez (2011). Nonparametric spatial regression of survival probability: visualization of population sinks in Eurasian Woodcock. Ecology [doi:10.1890/10-2224.1]

Péron G., Crochet P.A., Choquet R., Pradel R., Lebreton J.-D. and Gimenez O. (2010). Capture-recapture models with heterogeneity to study survival senescence in the wild. Oikos 119:524-532.

Péron G., Lebreton J.D. \& Crochet P.A (2010). Breeding dispersal in black-headed gull: the value of familiarity in a contrasted environment. Journal of Animal Ecology 79:317-326.

Plummer, M. (2003). JAGS: A Program for Analysis of Bayesian Graphical Models Using Gibbs Sampling, Proceedings of the 3rd International Workshop on Distributed Statistical Computing (DSC 2003), March 20-22, Vienna, Austria. ISSN 1609-395X.

Pradel, R. and Lebreton, J.-D. (1999) Comparison of different approaches to study the local recruitment of breeders. Bird Study 46:74-81.

Pradel R. (2005). Multievent: an extension of multistate Capture-Recapture Models to uncertain states. Biometrics 61:442-447.

Pradel R. (2009). The stakes of capture-recapture models with state uncertainty. In: Modeling Demographic Processes in Marked Populations (eds. Thomson DL, Cooch EG \& Conroy MJ). Springer Berlin, Germany, pp. 781-795. 
Pradel R., Choquet R., Lima M.A., Merritt J.F. \& Crespin L. (2010). Estimating population growth rate from capture-recapture data in presence of capture heterogeneity. Journal of Agricultural, Biological and Environmental Statistics 15:248-258.

Pradel R., Choquet R., \& Béchet A. (2011). Breeding experience might be a major determinant of breeding probability in long-lived species: the case of the greater flamingo. oai:hal.archives-ouvertes.fr:hal-00655507

R Development Core Team (2011). R: A language and environment for statistical computing. R Foundation for Statistical Computing, Vienna, Austria. ISBN 3-900051-07-0, URL http://www.R-project.org/.

Rouan L., Choquet R. \& Pradel R. (2009a). A general framework for modeling memory in capture-recapture data. Journal of Agricultural, Biological and Environmental Statistics $14: 338-355$

Rouan L., Gaillard J.-M., Y. Guédon \& Pradel R. (2009b). Estimation of Lifetime Reproductive Success When Reproductive Status Cannot Always Be Assessed. In: Modeling Demographic Processes in Marked Populations (eds. Thomson DL, Cooch EG \& Conroy MJ). Springer Berlin, Germany, pp. 867-879.

Royle, J. A. and Dorazio, R. M. 2008. Hierarchical modelling and inference in ecology. Academic Press.

Royle, J. A. 2008. Modeling individual effects in the Cormack-Jolly-Seber model: a statespace formulation. Biometrics 64:364-370.

Sanz-Aguilar A., Tavecchia G., Genovart M., Igual J.M., Oro D., Rouan L. \& Pradel R. (2011). Studying the reproductive skipping behavior in long-lived birds by adding nest-inspection to individual-based data. Ecological Applications 21:555-564.

Schaub, M., Gimenez, O., Sierro, A. and R. Arlettaz (2007). Use of Integrated Modeling to Enhance Estimates of Population Dynamics Obtained from Limited Data. Conservation Biology 21: 945-955. 
Schofield, M. R. and R. J. Barker. 2008. A Unified Capture-Recapture Framework. Journal of Agricultural Biological and Environmental Statistics 13:458-477.

Schofield, M. R. and R. J. Barker. 2011. Full open population capture-recapture models with individual covariates. Journal of Agricultural, Biological and Environmental Statistics $16: 253-268$.

Scofield, P., Fletcher, D. and C. Robertson (2001). Titi (Sooty Shearwaters) on Whero Island: An analysis of historic banding data using modern capture-recapture techniques. Journal of Agricultural, Biological and Environmental Statistics 6:268-280.

Seber, G.A.F. (1965) A note on the multiple-recapture census. Biometrika, 52:249-259.

Servanty, S., J.-M. Gaillard, Ronchi, F., Focardi, S., Baubet E. \& O. Gimenez (2011). Influence of harvesting pressure on demographic tactics: implications for wildlife management. Journal of Applied Ecology 48: 835-843

Servanty, S., R. Choquet, E. Baubet, S. Brandt, J.-M. Gaillard, M. Schaub, C. Toïgo, J.-D. Lebreton, M. Buoro and O. Gimenez (2010). Assessing whether mortality is additive using marked animals: a Bayesian state-space modeling approach. Ecology 91: 1916-1923

Tavecchia, G., J. Adrover, A. Muñoz Navarro, and R. Pradel (2012). Modelling mortality causes in longitudinal data in the presence of tag loss: application to raptor poisoning and electrocution. Journal of Applied Ecology 49:297-305

Toni, T. D. Welch, N. Strelkowa, A. Ipsen and M. P.H Stumpf (2009). Approximate Bayesian computation scheme for parameter inference and model selection in dynamical systems. J. R. Soc. Interface 6:187-202

Tuljapurkar, S. and H. Caswell, Structured-population models in marine, terrestrial, and freshwater systems. 1997, New York: Chapman and Hall.

de Valpine (2009). Shared challenges and common ground for Bayesian and classical analysis of hierarchical statistical models. Ecological Applications 19:584-588 
1 de Valpine, P. 2011. Frequentist analysis of hierarchical models for population dynamics and 2 demographic data. Journal of Ornithology doi: 10.1007/s10336-010-0642-5.

3 Van Tienderen, P. H. 2000. Elasticities and the link between demographic and evolutionary 4 dynamics. Ecology 81: 666-679.

5 Véran S., Gimenez O., Flint E., Kendall W.L., Doherty P.F. \& Lebreton J.-D. (2007).

6 Quantifying the impact of longline fisheries on adult survival in the black-footed albatross.

$7 \quad$ Journal of Applied Ecology 44:942-952.

8 Williams, B.K., Nichols, J.D. and Conroy, M.J. (2002) Analysis and management of animal 9 populations. Academic Press, San Diego.

10 
2 Figure 1: Three types of registration of a same discrete time survival process. Top: follow-up

3 data, bottom left: CJS models, bottom right: dead recovery models (see text for details). The

4 complete registration is a particular case of each of the two other ones.

5 Figure 2: Number of papers about Markov models (keywords 'Markov' or 'Markovian') in

6 human and animal population biology (keywords 'man or human' and 'animal or mammals or

7 birds' respectively) extracted from the Web of Science (search completed on the $9^{\text {th }}$ of August,

8 2011). Predicted trends were obtained from a Poisson regression in which both the year and the

9 type of population biology (human vs. animal) effects were significant on an additive scale.

10 Figure 3: Schematic representation of a hidden process model for an individual $i$ between two

11 sampling occasions $t-1$ and $t$. The first layer is a succession of hidden states (solid circles) or

12 latent states of individual $i$ at time $t\left(\mathrm{X}_{\mathrm{i}, \mathrm{t}}\right)$ depending on its states at time $t-1\left(\mathrm{X}_{\mathrm{i}, \mathrm{t}-1}\right)$. The

13 dynamic of the states is driven by transition probabilities, e.g., survival probability if states are

14 alive or dead. The second layer corresponds to observation or not of individual $i$ at time $t\left(\mathrm{Y}_{\mathrm{i}, \mathrm{t}}\right)$

15 conditional on individual $i$ being in state $\mathrm{X}_{\mathrm{i}, \mathrm{t}}$. These events are driven by some probabilities,

16 e.g., detection probabilities if observations are being captured or not. The observation process

17 is the visible part of the state process. Note that this representation holds for both hidden-

18 Markov models and state-space models.

19 Figure 4: Frequency distribution of lifetime reproductive success in roe deer. Error bars are +/-

201 'mean' standard deviation where 'mean' standard deviation was obtained as an average, for a

21 particular value of reproductive output, of all the individual LRS standard deviation for

22 individuals having this specific number of weaned offspring (see Appendix B for more details). 


\section{TABLE LEGENDS}

\section{Box 1: Glossary (alphabetical order)}

3 Table 1: Parameter maximum likelihood estimates (MLE) with standard errors (SE) for the

4 hidden-Markov model fitted to the titis data, with and without uncertainty in state assignment.

5 All parameters are probabilities. Note that the probability of remaining non-breeder and the

6 probability of making the transition from state breeder to state non-breeder are not displayed

7 but can be obtained as a complement.

8 Table 2: Monte Carlo parameter numerical summaries (posterior means with standard

9 deviations) from the state-space model fitted to the roe deer data. All parameters are

10 probabilities. Note that the probability of remaining in the same reproductive state is not

11 displayed but can be obtained as a complement. 


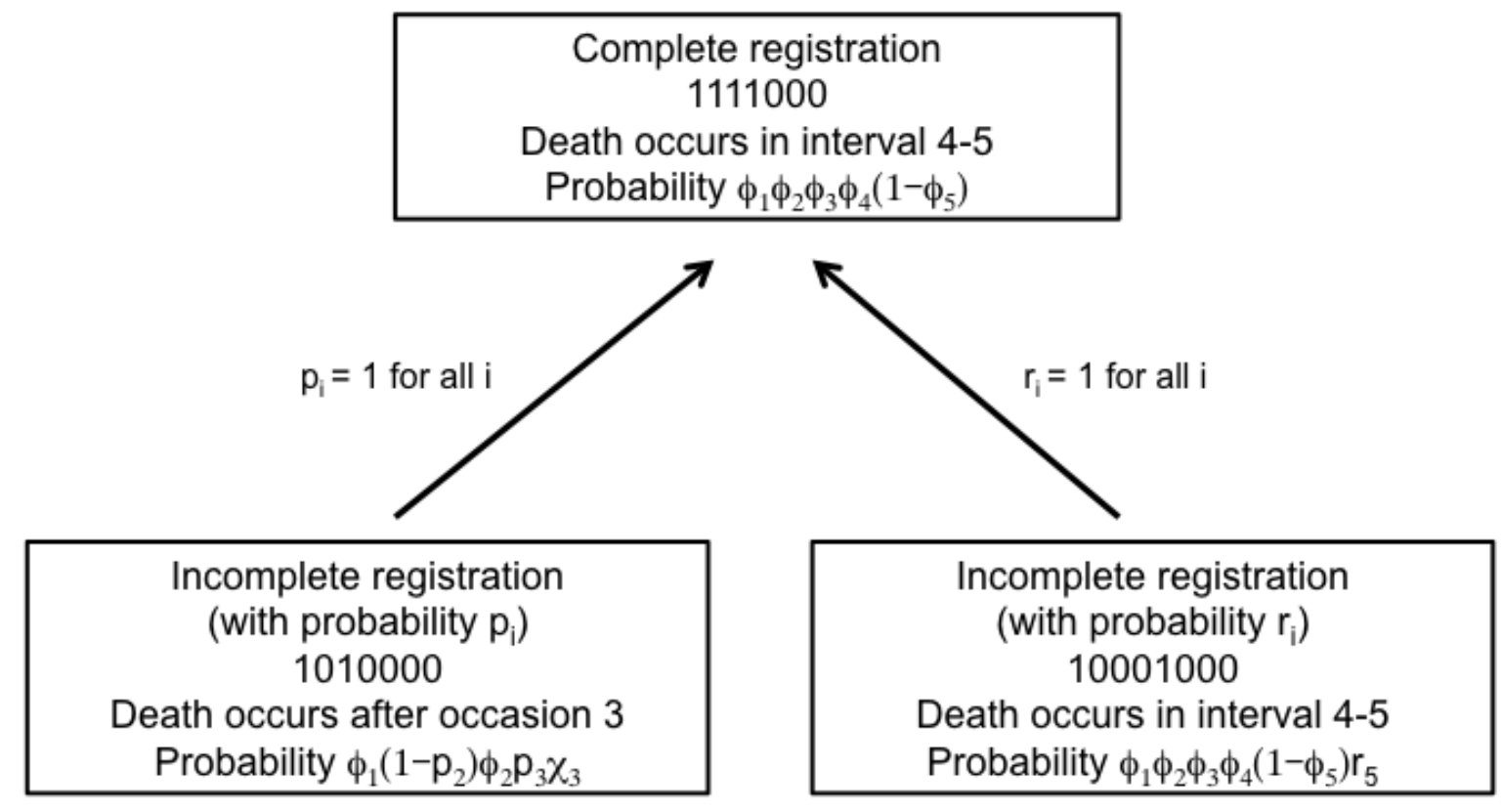


1 Figure 2:

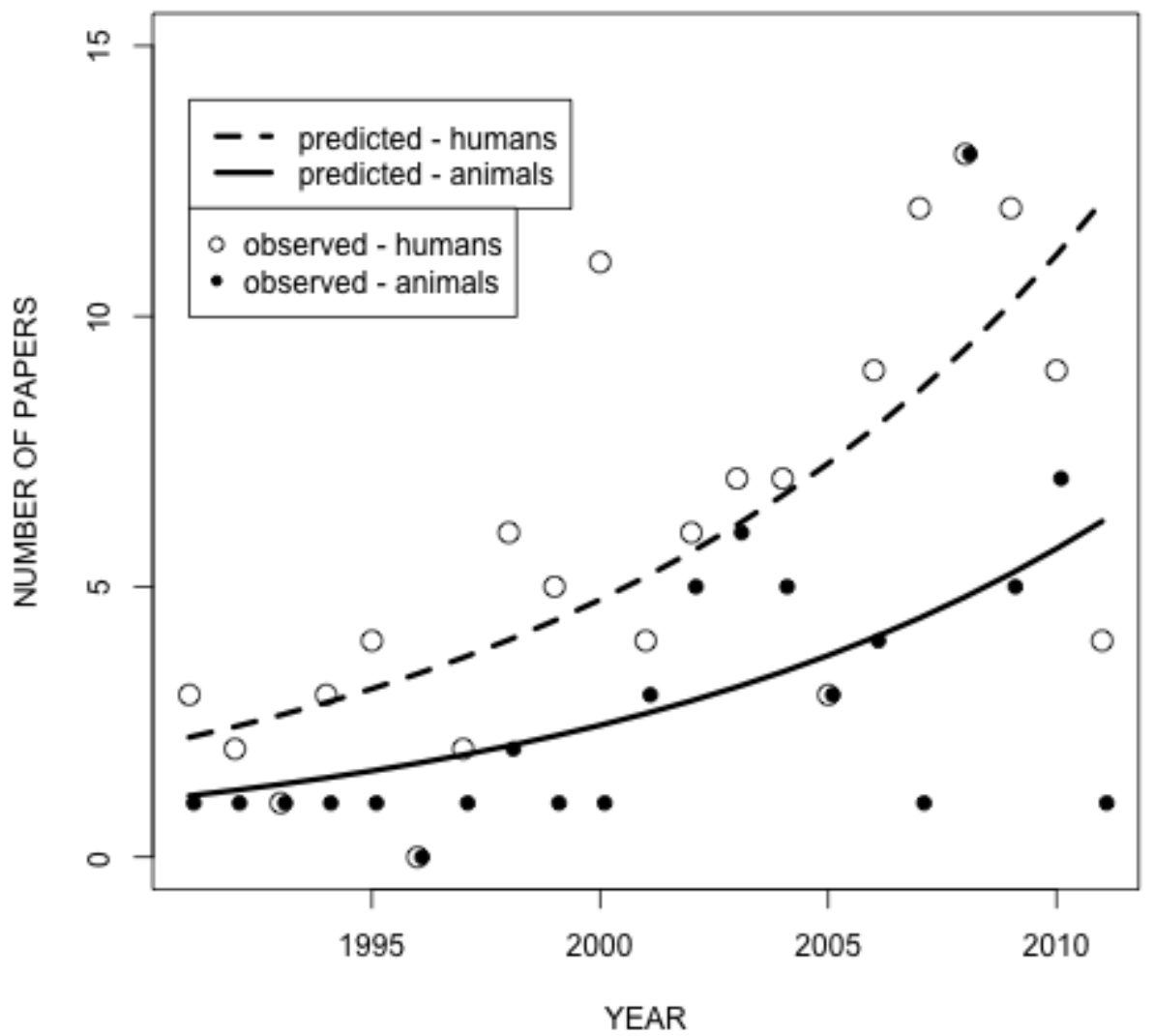


1 Figure 3:

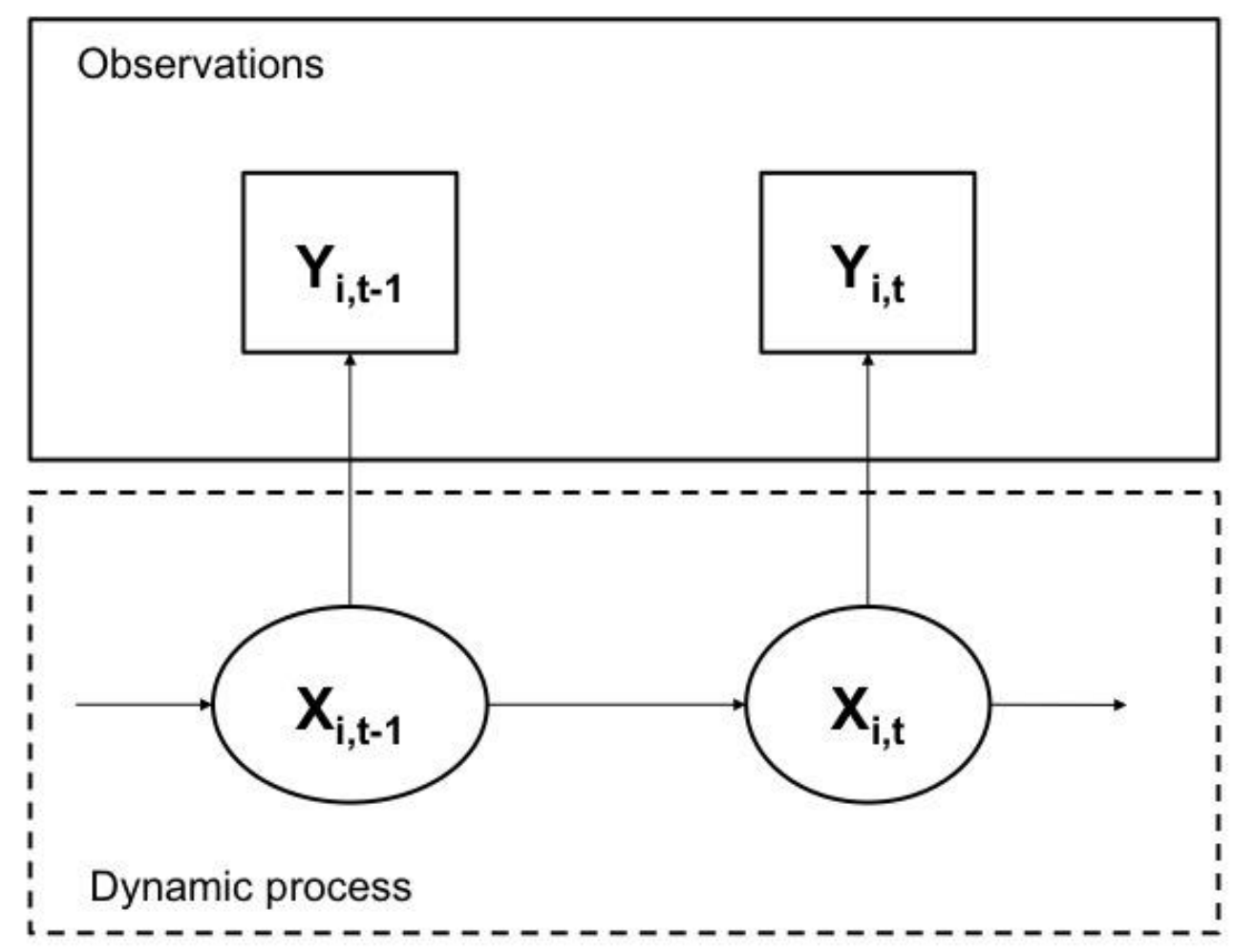


1 Figure 4:

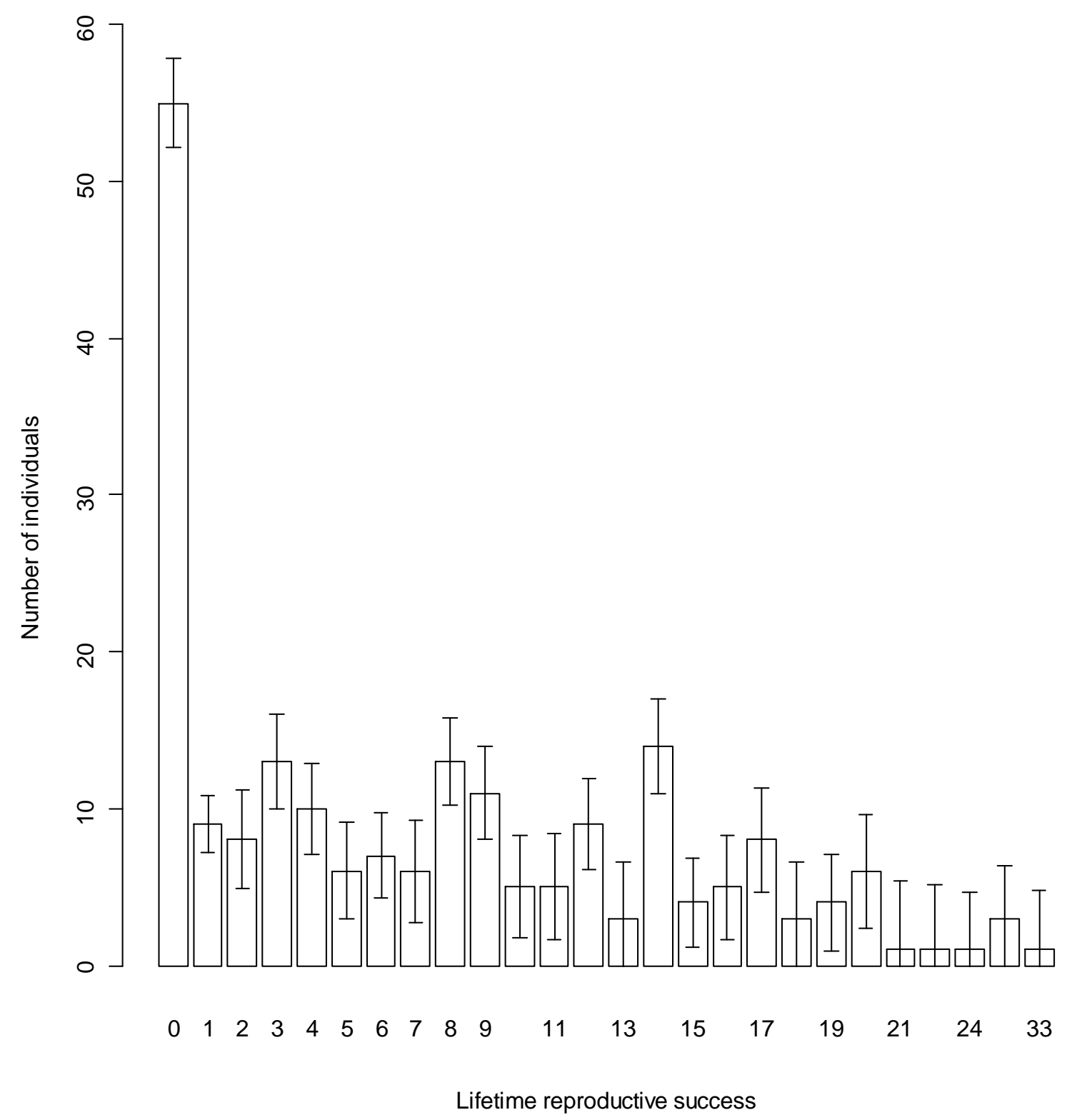

2 
Box 1:

2 CAPTURE-RECAPTURE (CR): A generic term embedding several protocols for monitoring

3 (mainly) plants and animals in the wild using marks to uniquely identify individuals. The

4 analysis of these data allows the estimation of, e.g., survival, dispersal and abundance while

5 explicitly accommodating for detection probability less than one.

6 CORMACK-JOLLY-SEBER MODEL (CJS): A capture-recapture model that is used for open

7 populations to estimate time-dependent survival and detection probabilities. The Cormack-

8 Jolly-Seber model is easily formulated as a hidden process model by considering two states

9 (alive or dead) and two observations or events (detected or not). The dynamic of states is

10 governed by a Markov model parameterized with survival probabilities while the observations

11 are made from these states according to detection probabilities.

12 Hidden MARKov MODEL (HMM): A particular case of state-space model in which the states

13 are Markovian, i.e. the next state depends only on the current state and not on the sequence of

14 states that occurred before.

15 HIDDEN PROCESS MODEL: A generic term referring to either a state-space model or a hidden

16 Markov model.

17 MulTiEvENT MODEL: A particular type of hidden Markov model. Multievent models

18 correspond to extensions of multistate models that allow accommodating uncertainty in state

19 assignment.

20 Multistate MODEL: An extension of the Cormack-Jolly-Seber model that allows estimation

21 of transition between states. Examples of such states are geographical sites, behavioral or

22 physiological conditions like, e.g., breeding vs. non-breeding or healthy vs. diseased.

23 STATE-SPACE MODEL (SSM): A model that runs two time series in parallel, one captures the

24 dynamic of the true states (latent) and the other consists of observations that are made from

25 these underlying but possibly unknown states. 


\begin{tabular}{c|cc}
\hline parameter & Reproductive state & Reproductive state \\
& uncertainty & uncertainty \\
modeled & ignored & $0.704(0.028)$ \\
survival of non-breeders $\phi^{\mathrm{NB}}$ & $0.704(0.014)$ & $0.814(0.016)$ \\
survival of breeders $\phi^{\mathrm{B}}$ & $0.801(0.016)$ & $0.837(0.019)$ \\
transition non-breeder to breeder $\psi^{\mathrm{NB} \rightarrow \mathrm{B}}$ & $0.249(0.021)$ & $0.219(0.025)$ \\
transition breeder to breeder $\psi^{\mathrm{B} \rightarrow \mathrm{B}}$ & $0.761(0.021)$ & $0.774(0.049)$ \\
detection of non-breeders $\mathrm{p}^{\mathrm{NB}}$ & $0.597(0.028)$ & $0.565(0.028)$ \\
detection of breeders $\mathrm{p}^{\mathrm{B}}$ & $0.563(0.027)$ & $0.598(0.032)$ \\
non-breeder state assignment $\delta^{\mathrm{NB}}$ & $\mathrm{NA}$ & $0.188(0.014)$ \\
breeder state assignment $\delta^{\mathrm{B}}$ & $\mathrm{NA}$ & $0.738(0.055)$ \\
\hline
\end{tabular}




\begin{tabular}{|c|c|}
\hline parameter & $\begin{array}{c}\text { posterior mean estimate } \\
\text { (standard deviation) }\end{array}$ \\
\hline transition non-breeder to weaning 1 fawn $\psi^{\mathrm{NB} \rightarrow \mathrm{BI}}$ & $0.160(0.033)$ \\
\hline transition non-breeder to weaning 2 fawns $\psi^{\mathrm{NB} \rightarrow \mathrm{B} 2}$ & $0.149(0.031)$ \\
\hline transition non-breeder to weaning 3 fawns $\psi^{\mathrm{NB} \rightarrow \mathrm{B} 3}$ & $0.208(0.036)$ \\
\hline transition weaning 1 fawn to non-breeder $\psi^{\mathrm{B} 1 \rightarrow \mathrm{NB}}$ & $0.274(0.067)$ \\
\hline transition weaning 1 to 2 fawns $\psi^{\mathrm{B} 1 \rightarrow \mathrm{B} 2}$ & $0.163(0.068)$ \\
\hline transition weaning 1 to 3 fawns $\psi^{\mathrm{B} 1 \rightarrow \mathrm{B} 3}$ & $0.316(0.086)$ \\
\hline transition weaning 2 fawns to non-breeder $\psi^{\mathrm{B} 2 \rightarrow \mathrm{NB}}$ & $0.229(0.059)$ \\
\hline transition weaning 2 to 1 fawns $\psi^{\mathrm{B} 2 \rightarrow \mathrm{B} 1}$ & $0.159(0.059)$ \\
\hline transition weaning 2 to 3 fawns $\psi^{\mathrm{B} 2 \rightarrow \mathrm{B} 3}$ & $0.302(0.082)$ \\
\hline transition weaning 3 fawns to non-breeder $\psi^{\mathrm{B} 3 \rightarrow \mathrm{NB}}$ & $0.261(0.048)$ \\
\hline transition weaning 3 to 1 fawns $\psi^{\mathrm{B} 3 \rightarrow \mathrm{B} 1}$ & $0.156(0.045)$ \\
\hline transition weaning 3 to 2 fawns $\psi^{\mathrm{B} 3 \rightarrow \mathrm{B} 2}$ & $0.224(0.052)$ \\
\hline detection of breeders $\mathrm{p}^{\mathrm{B}}$ & $0.341(0.032)$ \\
\hline detection of non-breeders $\mathrm{p}^{\mathrm{NB}}$ & $0.821(0.110)$ \\
\hline survival of yearling non-breeders $\phi^{\mathrm{NB}}(\mathrm{y})$ & $0.941(0.027)$ \\
\hline survival of prime-age non-breeders $\phi^{\mathrm{NB}}(\mathrm{pa})$ & $0.843(0.031)$ \\
\hline survival of old non-breeders $\phi^{\mathrm{NB}}(\mathrm{o})$ & $0.648(0.057)$ \\
\hline survival of prime-age non-breeders $\phi^{\mathrm{B}}(\mathrm{pa})$ & $0.934(0.019)$ \\
\hline survival of old non-breeders $\phi^{\mathrm{NB}}(\mathrm{o})$ & $0.831(0.030)$ \\
\hline
\end{tabular}


2 To fit the model without uncertainty in E-SURGE, three states are considered \{alive non-

3 breeder, alive breeder, dead $\}=\{\mathrm{NB}, \mathrm{B}, \mathrm{D}\}$, and the events are three as well $\{$ non-detected,

4 seen non-successful breeder, seen successful breeder $\}=\{0,1,2\}$.

5 In GEPAT, declare two steps for the transitions (survival then conditional transitions).

6 Initial state: $\Pi=\left[\begin{array}{lll}\pi & * & -\end{array}\right]$

7

8 Transition 1 (survival): $S=\left[\begin{array}{ccc}\phi & - & * \\ - & \phi & * \\ - & - & *\end{array}\right]$

9 Transition 2 (conditional transition): $T=\left[\begin{array}{ccc}* & \psi & - \\ \psi & * & - \\ - & - & *\end{array}\right]$

10

11 Event: $C=\left[\begin{array}{ccc}* & \beta & - \\ * & - & \beta \\ * & - & -\end{array}\right]$

12

13

14

15

16

17

18

19

20

21

22 To fit the model with uncertainty in E-SURGE, the same three states are required \{alive non-

23 breeder, alive breeder, dead $\}=\{\mathrm{NB}, \mathrm{B}, \mathrm{D}\}$, but the events are four $\{$ non-detected, seen and

24 ascertained as non-breeder, seen and ascertained as breeder, not ascertained $\}=\{0,1,2,3\}$.

25 In GEPAT, declare two steps for the transitions (survival then conditional transitions) and two

26 steps for the events (capture then ascertainment).

27 Initial state: $\Pi=\left[\begin{array}{lll}\pi & * & -\end{array}\right]$

28 Transition 1 (survival): $S=\left[\begin{array}{ccc}\phi & - & * \\ - & \phi & * \\ - & - & *\end{array}\right]$ 
1 Transition 2 (conditional transition): $T=\left[\begin{array}{ccc}* & \psi & - \\ \psi & * & - \\ - & - & *\end{array}\right]$

2

3 Event 1 (capture): $C=\left[\begin{array}{ccc}* & \beta & - \\ * & - & \beta \\ * & - & -\end{array}\right]$

4 Event 2 (ascertainment): $A=\left[\begin{array}{cccc}* & - & - & - \\ - & \delta & - & * \\ - & - & \delta & *\end{array}\right]$

5

6 In GEMACO, the syntax is:

7

8 For Initial State: IS = i

9 For Transition:

$10 \quad$ S (i.e. step 1$)=\mathrm{f}$

$11 \quad \mathrm{~T}$ (i.e. step 2) $=\mathrm{f}$

12 For Event:

$13 \quad$ C (i.e. step 1$)=$ firste + nexte.f

14 A (i.e. step 2 ) $=\mathrm{f}$

15

16 


\section{Appendix A2. R Code for generating uncertainty in titis data}

2 To artificially generate uncertainty on both the states non-breeder and breeder, we used the R

3 script below to alter the raw capture-recapture data

4

5 \# original data are stored in R matrix titi with individuals in rows and years in columns

$6 \quad \# 1$ seen as non-breeder

$7 \quad \# 2$ seen as breeder

8 \# 0 not seen

9

\# nb of capture occasions

ny $<-$ ncol(titi)

\# nb of individuals

nind <- nrow(titi)

\# the amended data with uncertainty are stored in R matrix titi2

titi2 <- titi

for (i in 1:nind)

\{

for ( $\mathrm{j}$ in $1: n y)\{$

\# 1 seen and ascertained Non-Breeder (with probability .2)

\# 2 seen and ascertained Breeder (with probability .7)

\# 3 seen but not ascertained (Non-Breeders with probability $.8+$ Breeders with probability .3 )

\# 0 not seen

\# Non-Breeders are ascertained with probability .2

if $(\mathrm{titi}[\mathrm{i}, \mathrm{j}]==1)$

\{

temp <- rbinom $(1$, size $=1$, prob $=.2)$

if (temp ==1) titi2[i,j] <- 1 \# if ascertained NB, event $=1$

if (temp $==0)$ titi2 $[\mathrm{i}, \mathrm{j}]<-3$ \# if not ascertained, event $=3$

\}

\# Breeders are ascertained with probability .7 (event $=1)$,

\# or not ascertained with probability $.3($ event $=2)$

if $(\operatorname{titi}[\mathrm{i}, \mathrm{j}]==2)$

\{

temp <- rbinom $(1$, size $=1$, prob $=.7)$

if (temp $==1$ ) titi2 $[i, j]<-2$ \# if ascertained B, event $=2$

if (temp $==0)$ titi2 $[\mathrm{i}, \mathrm{j}]<-3$ \# if not ascertained, event $=3$

41

42

43

44

45

46 
2

3

4

5

6

7

8

9

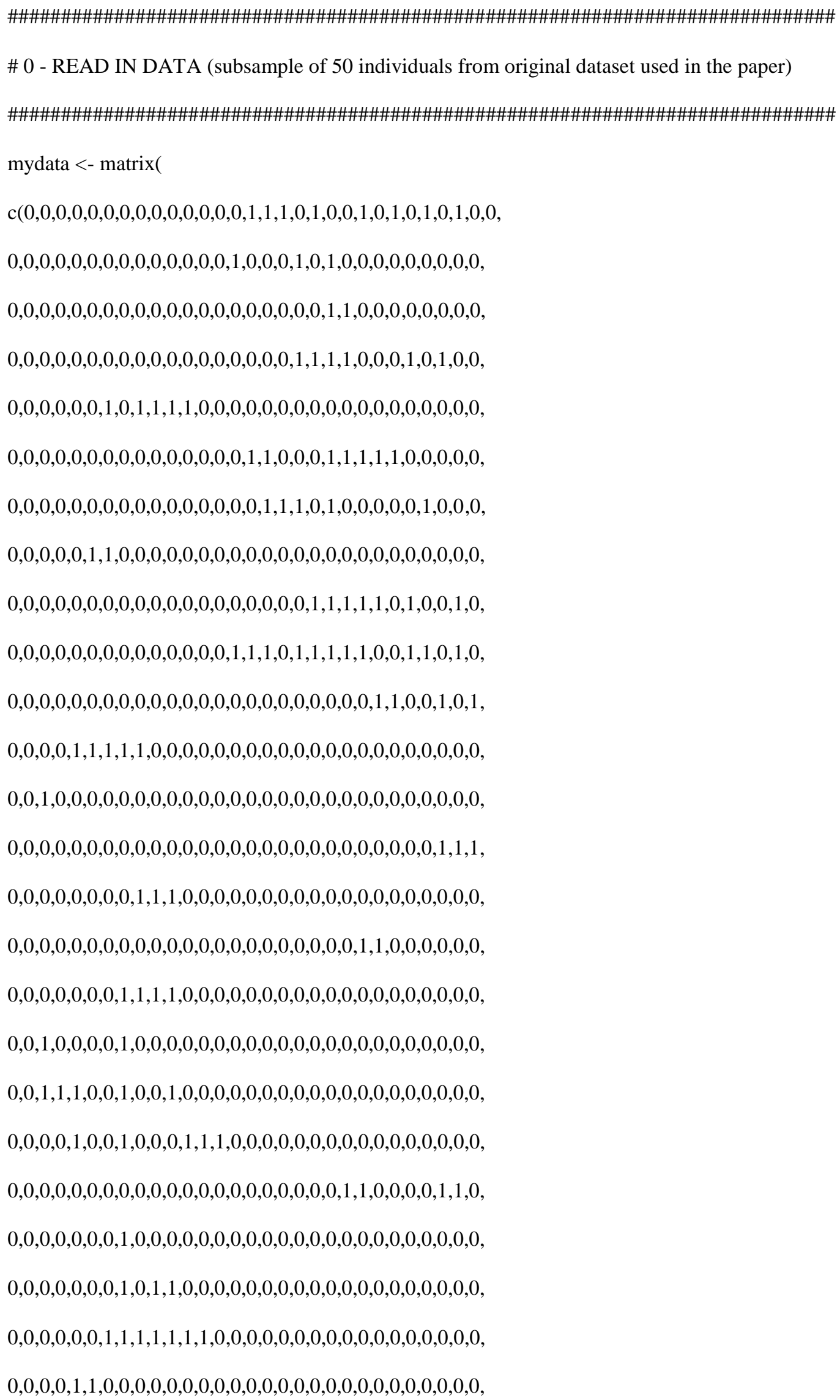




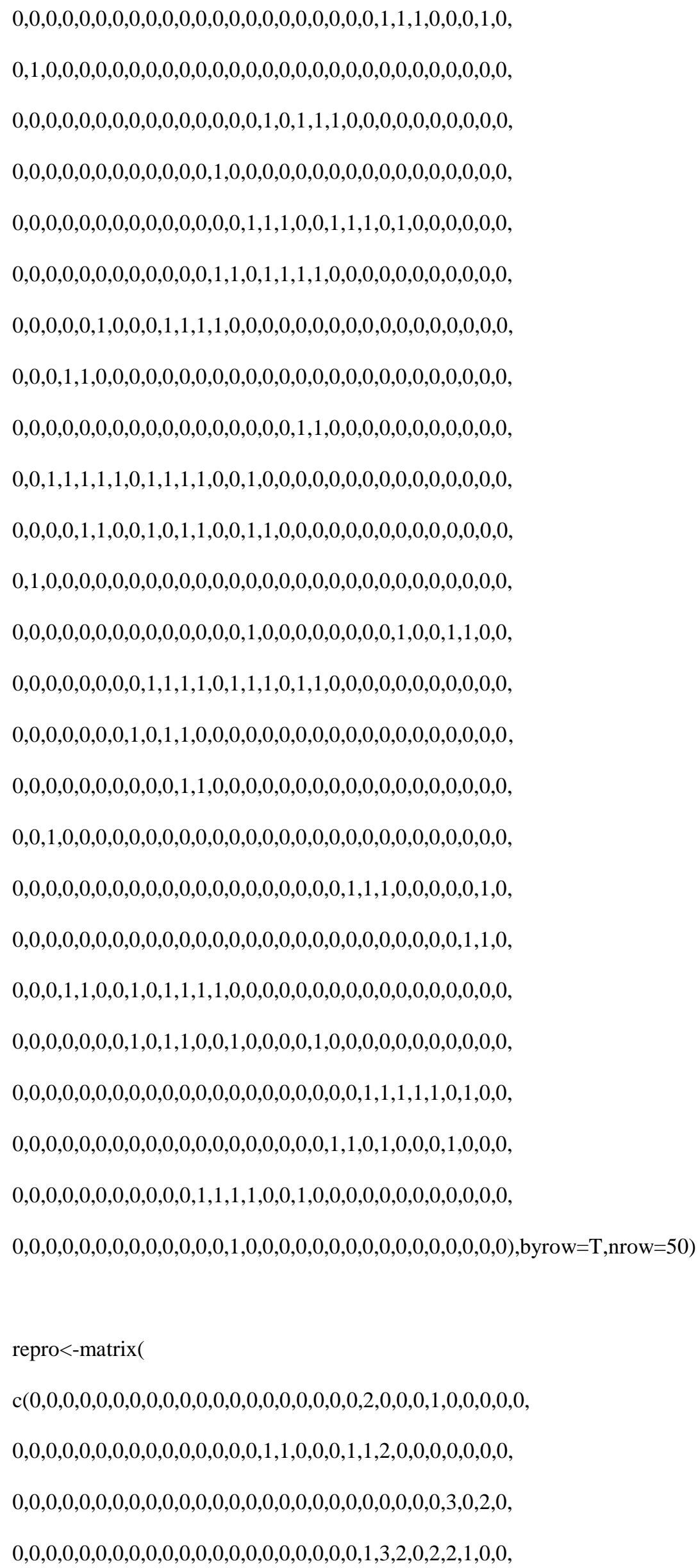




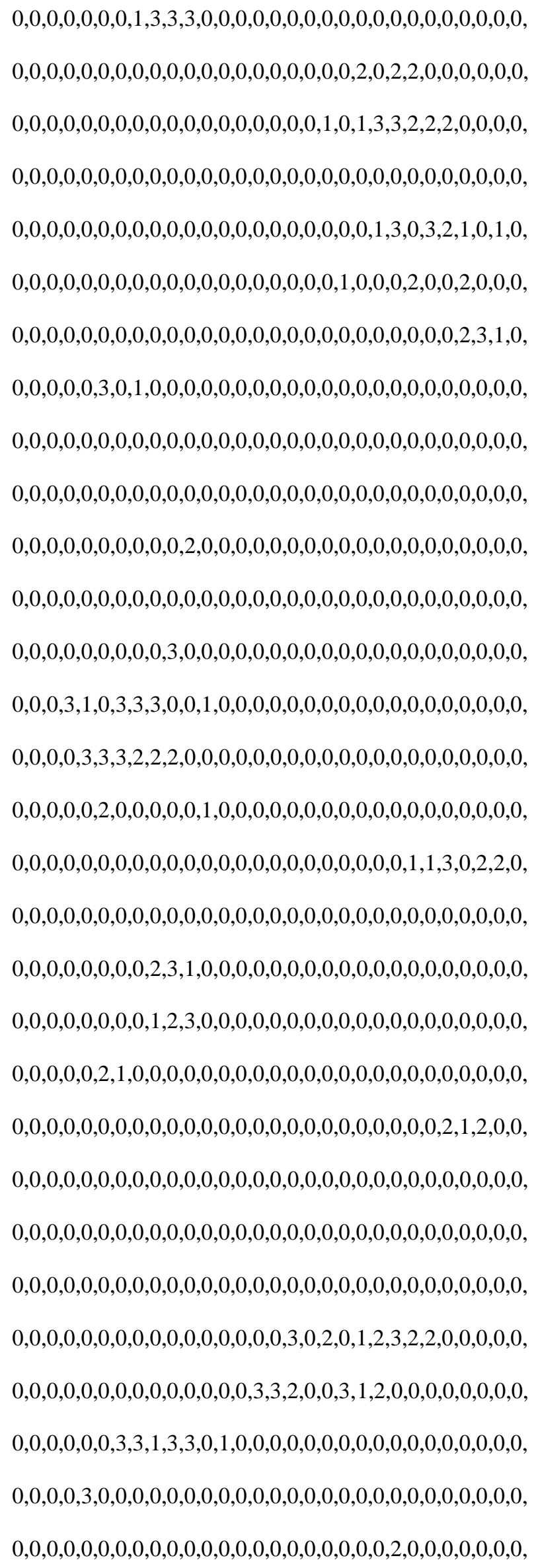




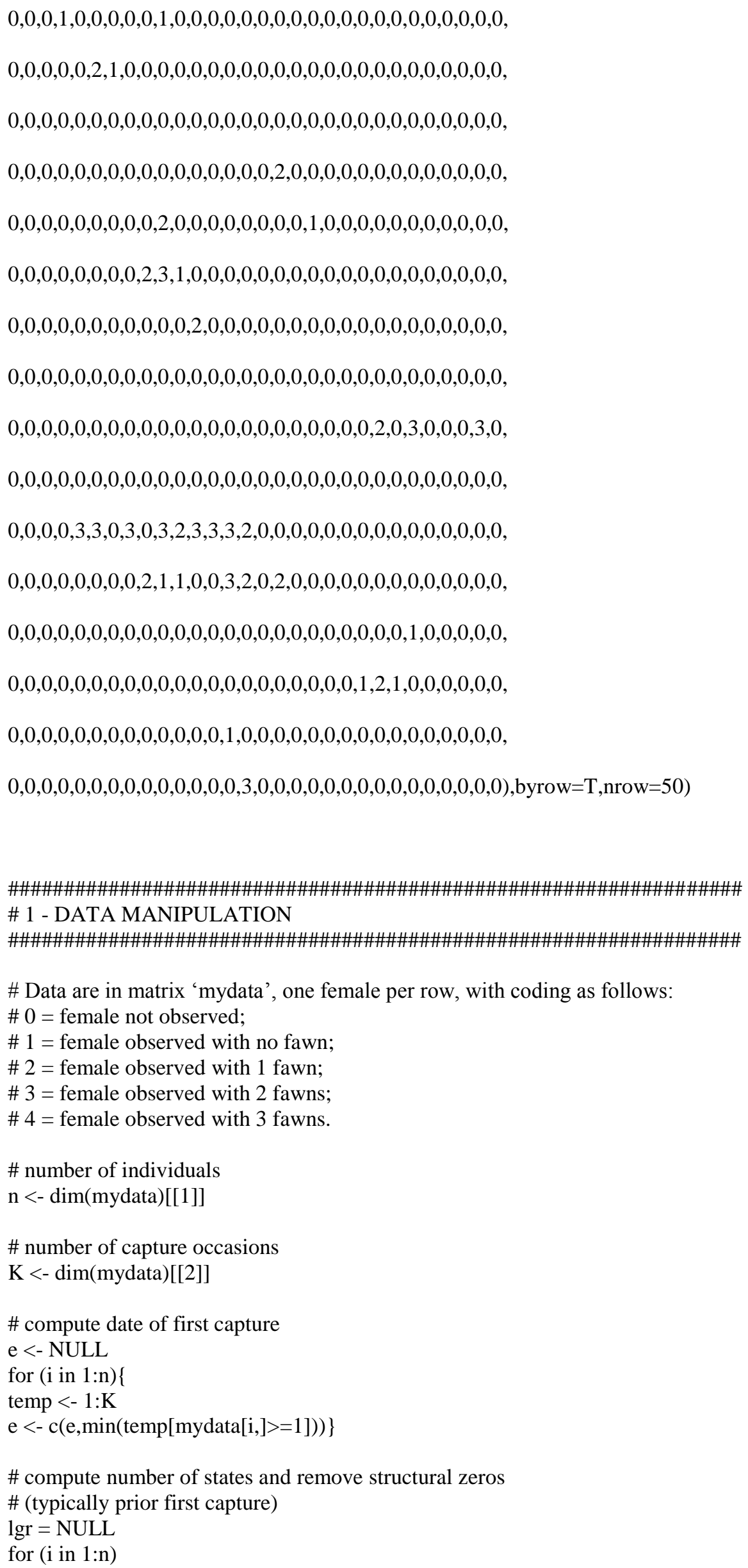




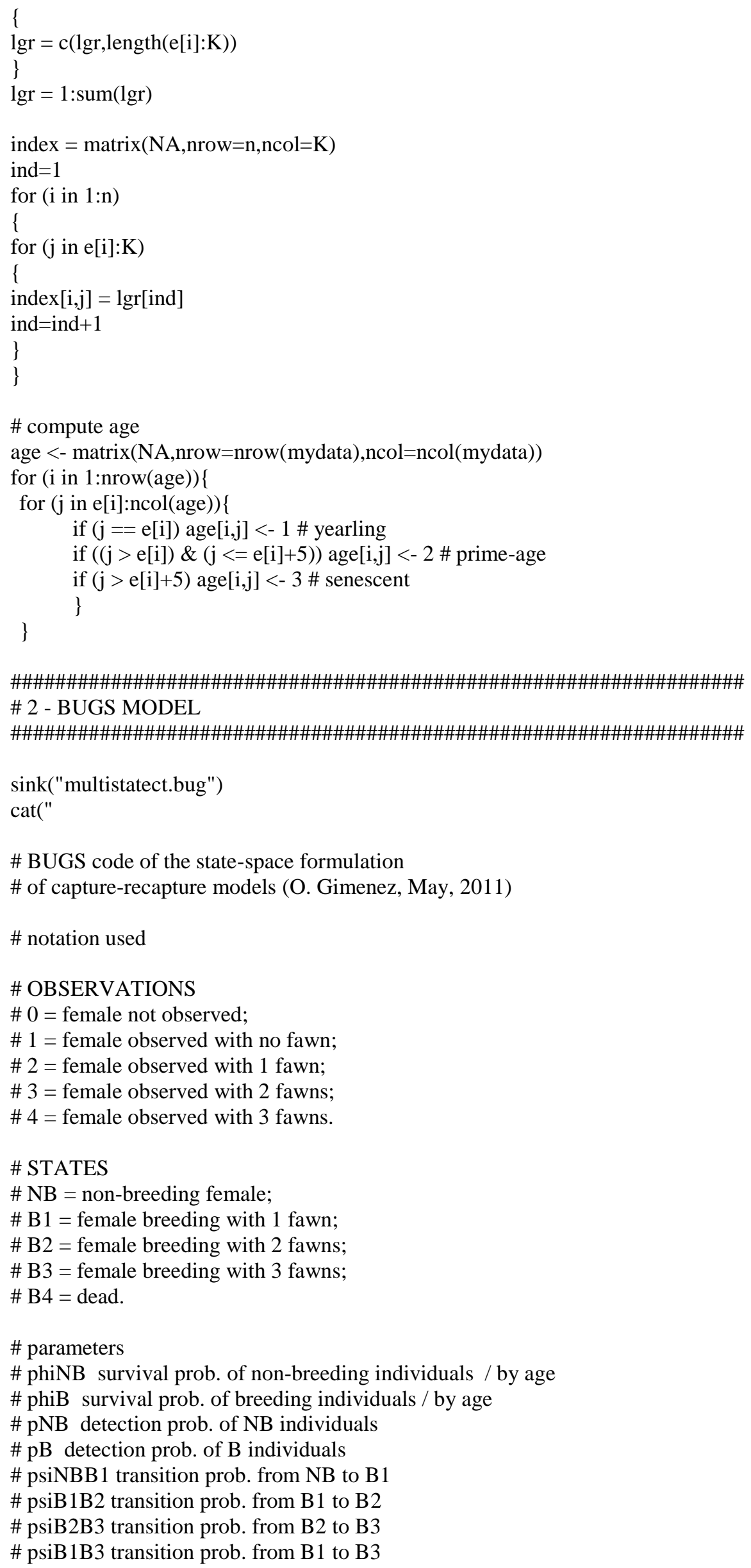




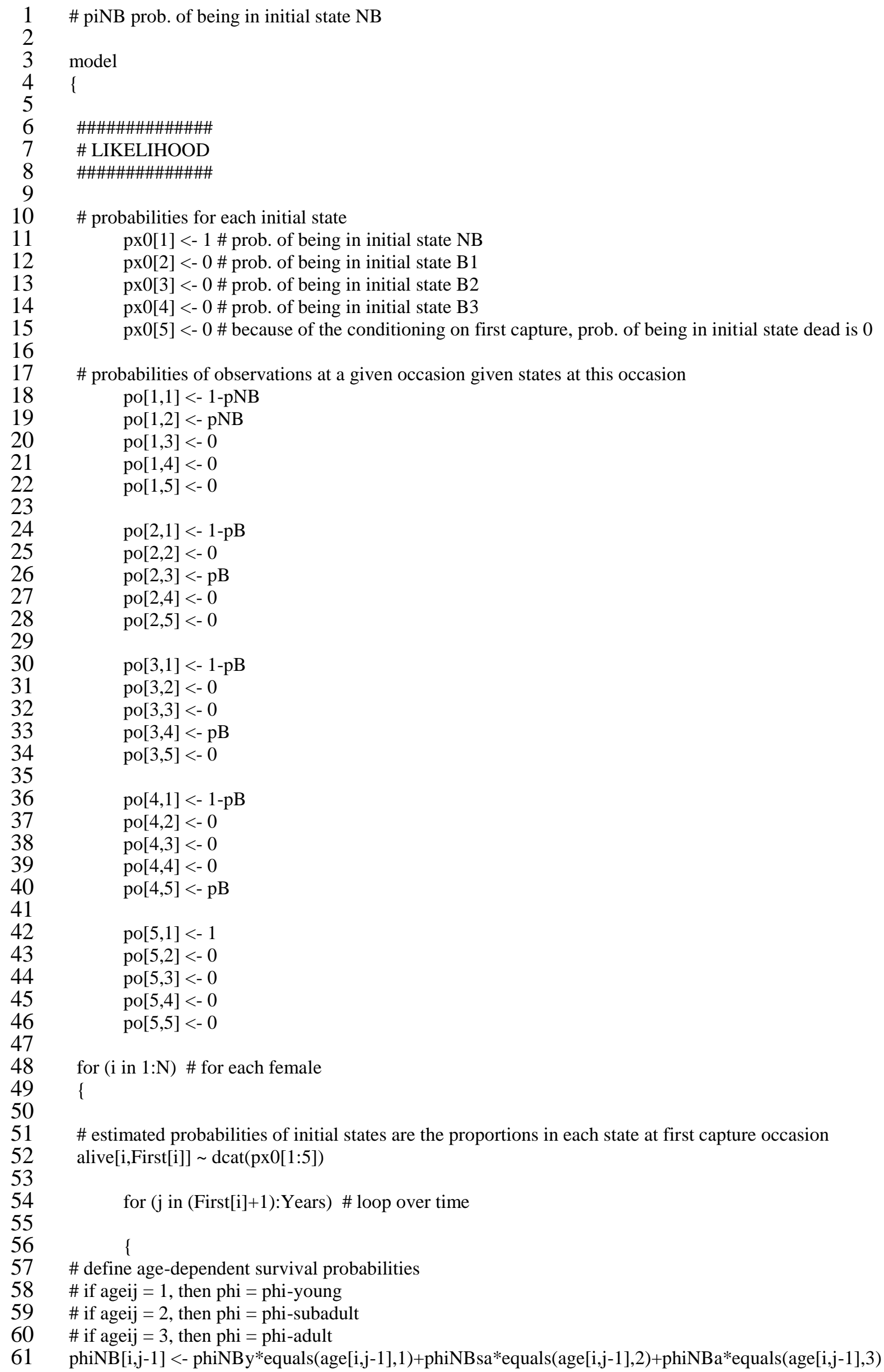




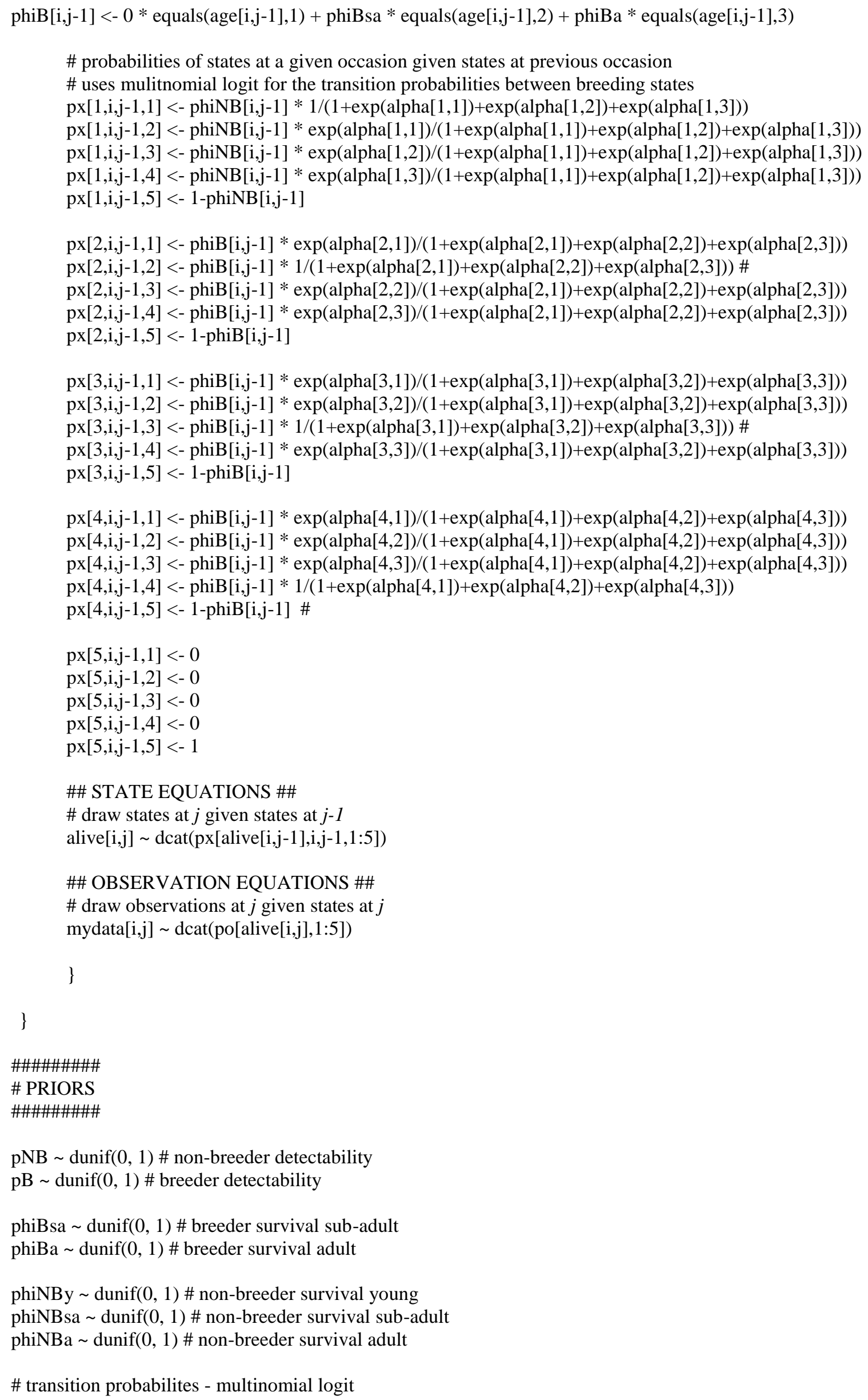




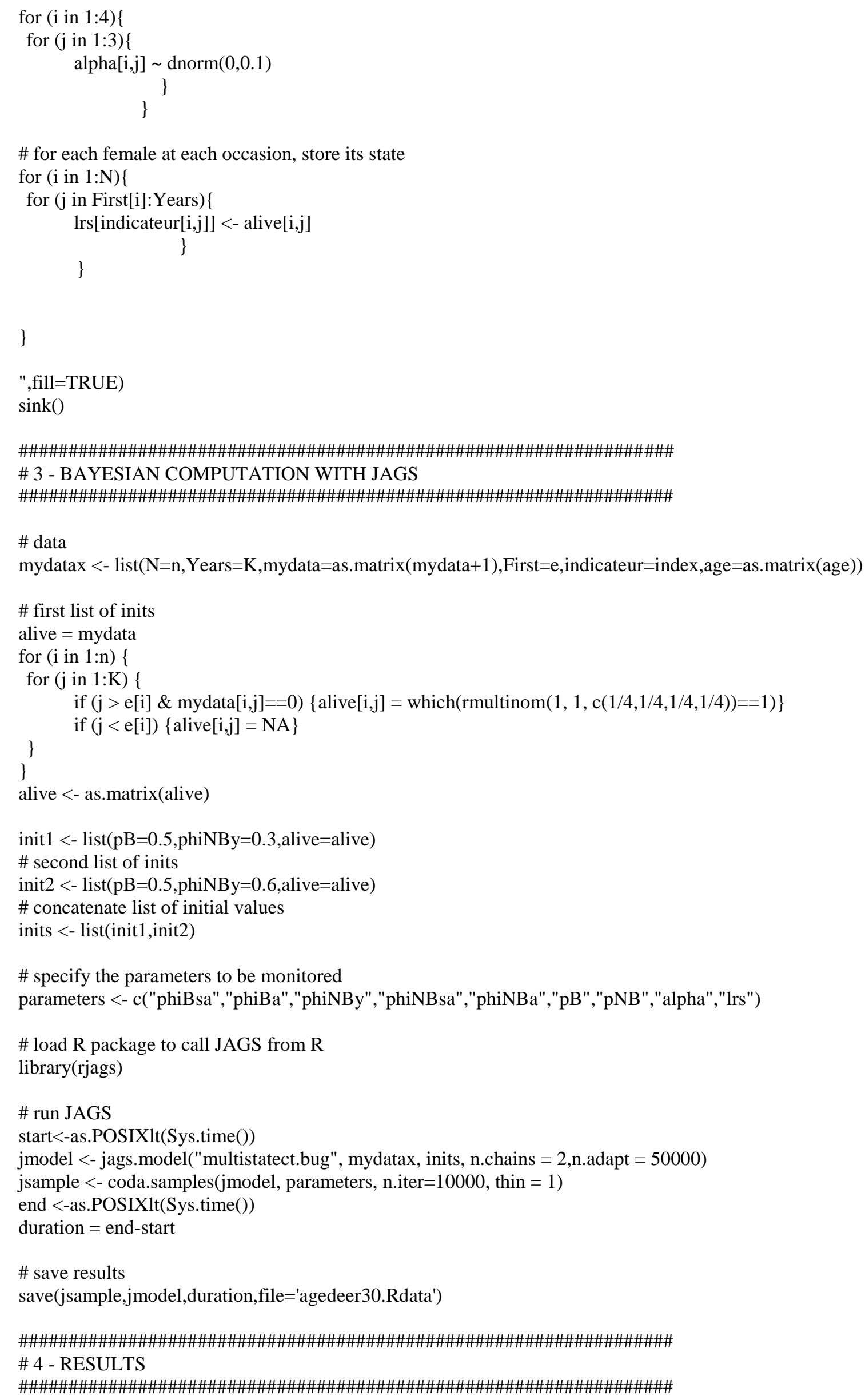


1

\# check convergence

$\operatorname{plot}($ jsample, trace $=$ TRUE, density $=$ FALSE, ask $=$ dev.interactive ()$)$

gelman.diag(jsample)

\# numerical summaries and posterior distributions

summary(jsample)

$\operatorname{plot}($ jsample, trace $=$ FALSE, density $=$ TRUE, ask $=$ dev.interactive ()$)$

\#-- display transition probabilities (back-transformation using inverse multinomial logit)

\# psiNBNB psiNBB1 psiNBB2 psiNBB3

a12 <- c(jsample[[1]][,'alpha[1,1]'],jsample[[2]][,'alpha[1,1]'])

a13 <- c(jsample[[1]][,'alpha[1,2]'],jsample[[2]][',alpha[1,2]'])

a14 <- c(jsample[[1]][,'alpha[1,3]'],jsample[[2]][,'alpha[1,3]'])

a11 <- rep(0,length(a12)) \#\# ref

a1<-cbind(a11,a12,a13,a14)

apply(exp(a1)/apply(exp(a1),1,sum),2,mean)

apply(exp(a1)/apply(exp(a1),1,sum),2,sd)

\# psiB1NB psiB1B1 psiB1B2 psiB1B3

a21 <- c(jsample[[1]][,'alpha[2,1]'],jsample[[2]][,'alpha[2,1]'])

a23 <- c(jsample[[1]][,'alpha[2,2]'],jsample[[2]]['alpha[2,2]'])

a24 <- c(jsample[[1]][,'alpha[2,3]'],jsample[[2]][',alpha[2,3]'])

a22 <- rep(0,length(a21)) \#\# ref

a2<-cbind(a21,a22,a23,a24)

apply(exp(a2)/apply(exp(a2),1,sum),2,mean)

apply(exp(a2)/apply(exp(a2),1,sum),2,sd)

\# psiB2NB psiB2B1 psiB2B2 psiB2B3

a31 <- c(jsample[[1]][,'alpha[3,1]'],jsample[[2]][,'alpha[3,1]'])

a32 <- c(jsample[[1]][,'alpha[3,2]'],jsample[[2]][,'alpha[3,2]'])

a34 <- c(jsample[[1]][,'alpha[3,3]'],jsample[[2]][,'alpha[3,3]'])

a33 <- rep $(0$, length $(\mathrm{a} 31))$ \#\# ref

a3<-cbind(a31,a32,a33,a34)

apply(exp(a3)/apply(exp(a3),1,sum),2, mean)

apply(exp(a3)/apply(exp(a3),1,sum),2,sd)

\# psiB3NB psiB3B1 psiB3B2 psiB3B3

a41 <- c(jsample[[1]][,'alpha[4,1]'],jsample[[2]][,'alpha[4,1]'])

a42 <- c(jsample[[1]][,'alpha[4,2]'],jsample[[2]][,'alpha[4,2]'])

a43 <- c(jsample[[1]]['alpha[4,3]'],jsample[[2]]['alpha[4,3]'])

a44 <- rep(0,length(a41)) \#\# ref

a4<-cbind(a41,a42,a43,a44)

apply(exp(a4)/apply(exp(a4),1,sum),2, mean)

apply(exp(a4)/apply(exp(a4),1,sum),2,sd)

\#----- compute LRS

\# merge two MCMC chains

res <- rbind(jsample[[1]],jsample[[2]])

$\operatorname{dim}(\mathrm{res}) \# 20000$ x 962

lrs <- res[,13:955]

$\operatorname{dim}(\operatorname{lrs})$

\# number of simulations

nrowarray $=\operatorname{dim}(\operatorname{lrs})[1]$

\# matrix of estimated states

lrsind $=\operatorname{array}(\mathrm{NA}, \mathrm{c}($ nrowarray, $, \mathrm{K}, \mathrm{K}))$

for ( $\mathrm{k}$ in 1 :nrowarray) 


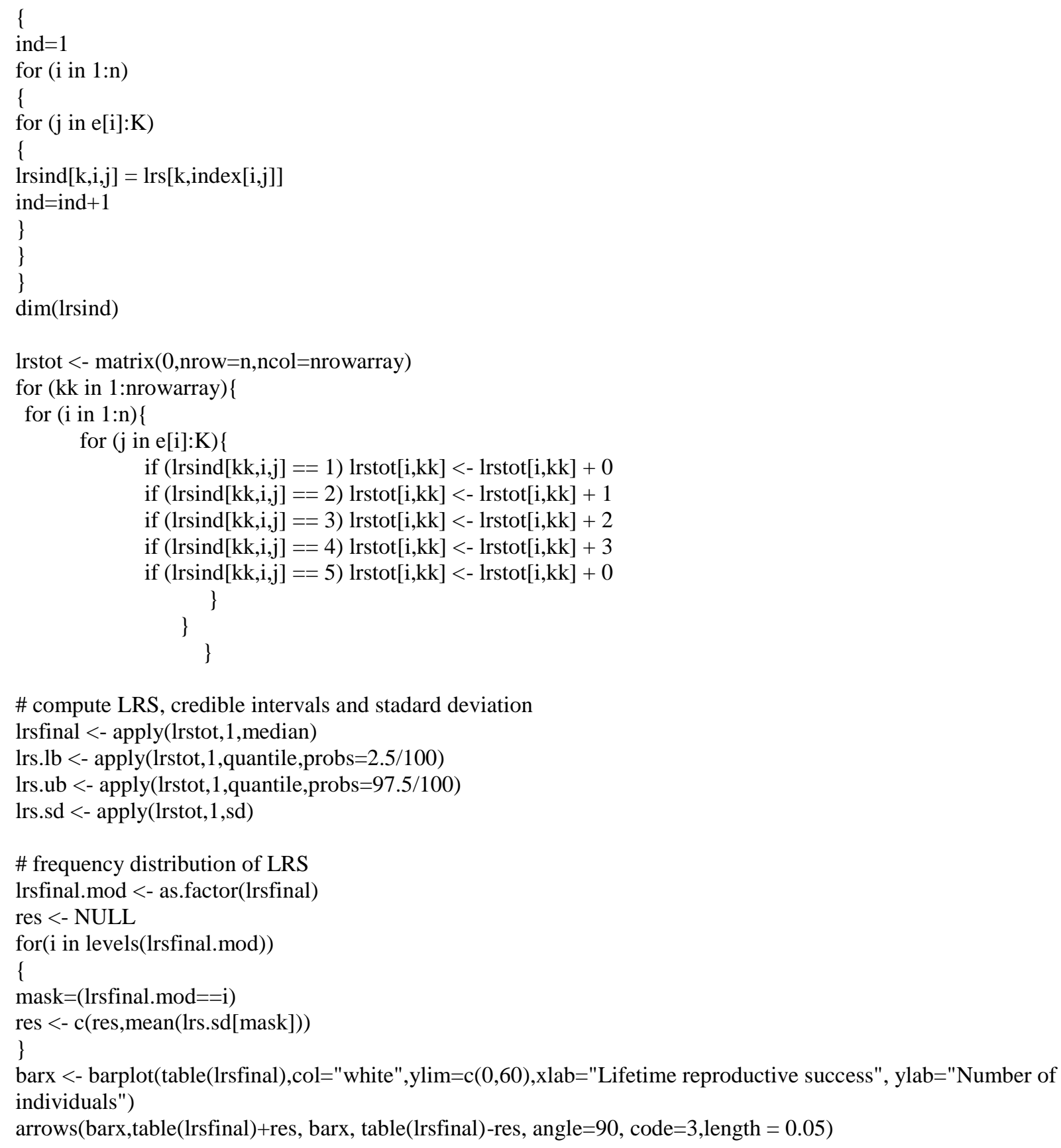

